\title{
Non-visual Opsins and Novel Photo-Detectors in the Vertebrate Inner Retina Mediate Light Responses Within the Blue Spectrum Region
}

\author{
Mario E. Guido ${ }^{1,2}\left(\right.$. Natalia A. Marchese ${ }^{1,2} \cdot$ Maximiliano N. Rios $^{1,2} \cdot$ Luis P. Morera $^{3} \cdot$ Nicolás M. Diaz $^{4}$. \\ Eduardo Garbarino-Pico ${ }^{1,2} \cdot$ María Ana Contin ${ }^{1,2}$
}

Received: 7 August 2020 / Accepted: 3 November 2020

○) Springer Science+Business Media, LLC, part of Springer Nature 2020

\begin{abstract}
In recent decades, a number of novel non-visual opsin photopigments belonging to the family of G protein- coupled receptors, likely involved in a number of non-image-forming processes, have been identified and characterized in cells of the inner retina of vertebrates. It is now known that the vertebrate retina is composed of visual photoreceptor cones and rods responsible for diurnal/color and nocturnal/black and white vision, and cells like the intrinsically photosensitive retinal ganglion cells (ipRGCs) and photosensitive horizontal cells in the inner retina, both detecting blue light and expressing the photopigment melanopsin (Opn4). Remarkably, these non-visual photopigments can continue to operate even in the absence of vision under retinal degeneration. Moreover, inner retinal neurons and Müller glial cells have been shown to express other photopigments such as the photoisomerase retinal G protein-coupled receptor (RGR), encephalopsin (Opn3), and neuropsin (Opn5), all able to detect blue/violet light and implicated in chromophore recycling, retinal clock synchronization, neuronto-glia communication, and other activities. The discovery of these new photopigments in the inner retina of vertebrates is strong evidence of novel light-regulated activities. This review focuses on the features, localization, photocascade, and putative functions of these novel non-visual opsins in an attempt to shed light on their role in the inner retina of vertebrates and in the physiology of the whole organism.
\end{abstract}

Keywords Retina $\cdot$ Light responses $\cdot$ Opsin $\cdot$ Non-visual photopigment $\cdot$ Non-image forming activity $\cdot$ Circadian rhythm $\cdot$ Blue light

Natalia A. Marchese and Maximiliano N. Rios are contributed equally to this work.

\section{Mario E. Guido}

mguido@fcq.unc.edu.ar

1 CIQUIBIC-CONICET, Facultad de Ciencias Químicas, Universidad Nacional de Córdoba, 5000 Córdoba, Argentina

2 Departamento de Química Biológica "Ranwel Caputto", Facultad de Ciencias Químicas, Universidad Nacional de Córdoba, 5000 Córdoba, Argentina

3 Present Address: Instituto de Organizaciones Saludables, Universidad Siglo 21, Córdoba, Argentina

4 Present Address: Department of Ophthalmology, University of Washington School of Medicine, 750 Republican St., Campus, Box 358058, Seattle, WA 98109, USA

\section{The Vertebrate Retina and Visual/Non-visual Photoreceptors}

Beyond the ability of the retina to detect light for visual processing and image formation, the inner retina of vertebrates has acquired a number of cells expressing non-visual photopigments potentially implicated in photoreception in the visible wavelengths of the spectrum mainly concentrated in the blue region; such non-visual photopigments appear to be involved in several non-image forming (NIF) activities, such as the setting of the intrinsic biological clock for the whole organism and of that located in the retina itself, pupillary light reflexes (PLRs), inhibition of pineal melatonin production, circadian control of sleep, mood, chromophore recycling, and a number of other activities related to neuronto-glia communication (Guido et al. 2010; Díaz et al. 2016). In order to carry out these functions, the vertebrate retina is made up of five major classes of neurons [visual photoreceptor cells (PRCs), horizontal cells, bipolar cells, amacrine 
cells, ganglion cells (RGCs)] and glial cells (Tessier-Lavigne and Placzek 1991) (see Fig. 1). Retinal neurons are linked via a complex pattern of connections, but with an orderly, layered anatomical arrangement. The structural organization of the retina comprises three nuclear layers: outer nuclear layer (ONL), inner nuclear layer (INL), and ganglion cell layer (GCL) (see Fig. 1). PRCs are adjacent to the retinal pigment epithelium (RPE) at the back of the eye. PRCs, bipolar cells, and horizontal cells form synaptic connections with each other in the outer plexiform layer (OPL), whereas bipolar cells, amacrine cells, and RGCs make contact in the inner plexiform layer (IPL) (see Fig. 1). Among glial cells, Müller glial cells are the most abundant in the retina, existing throughout the entire inner retina and responsible for diverse essential metabolic and physiological functions, significantly contributing to homeostasis and even more complex processes such as neuronal regeneration.

In most parts of the retina, light passes through layers of nerve cells (GCL and INL) and their processes (IPL and OPL) before reaching the PRCs. After photoreception, information flows vertically from PRCs to bipolar cells and to RGCs. Information also flows laterally, mediated by horizontal cells in OPL and amacrine cells in the IPL. Light reaching the retina provides the animal with an extended wavelength "daylight" stimulus ranging from 400 to $600 \mathrm{~nm}$.
This is mediated by rod PRCs with the photopigment rhodopsin (Opn2) and cones expressing diverse cone opsins (Opn1) such as the long-wave-sensitive (LWS) red cones, mid-wave-sensitive (MWS) green cones, and short-wavesensitive (SWS) blue cones (Bowmaker et al. 1997). Some vertebrates including avian species are also sensitive to UV light and have specific photoreceptors in this range, the socalled UV-sensitive or violet cones with maximum absorbance around $418 \mathrm{~nm}$. In addition to vision and photopigments directly involved in image-forming activities, a new set of photopigments has been reported in the vertebrate retina-the so-called non-visual opsins such as melanopsins (Opn4M and Opn4X) (Provencio et al. 2000; Chaurasia et al. 2005; Bellingham et al. 2006; Contin et al. 2006, 2010; Verra et al. 2011) encephalopsin (Opn3) (Rios et al. 2019), neuropsin (Opn5) (Yamashita et al. 2010; Kojima et al. 2011; Nieto et al. 2011; Rios et al. 2019) and the photoisomerase Retinal G protein-coupled receptor (RGR) (Díaz et al. 2017). The visual opsins (Opn1 and Opn2) together with the various non-visual opsins (Opn3, Opn4, Opn5), acting particularly on the violet/blue light portion of the spectrum, provide vertebrates with the evolutionary advantage of photosensitivity in a broader spectrum region (Fig. 2).

The visual PRCs in all vertebrate species, comprising cones (Opn1 cells) and rods (Opn2 cells), are specialized

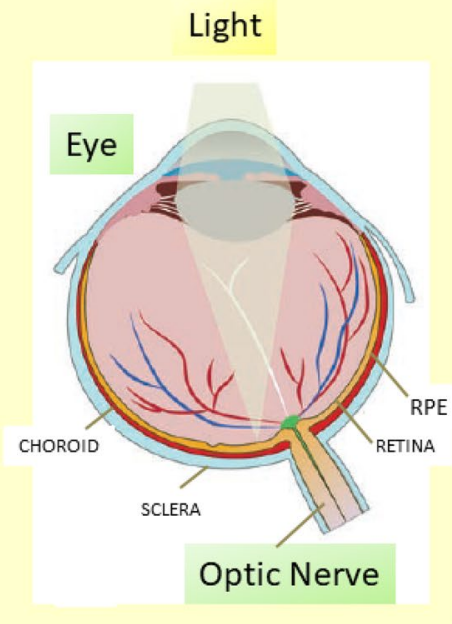

Normal Retina

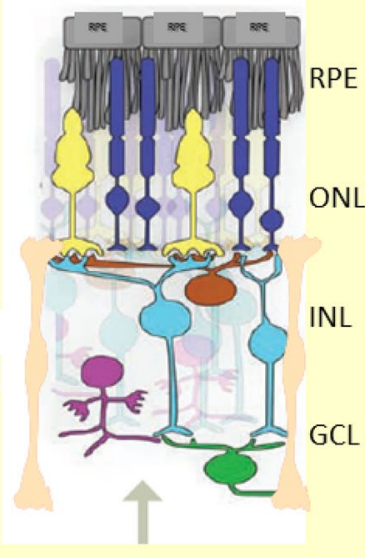

Light

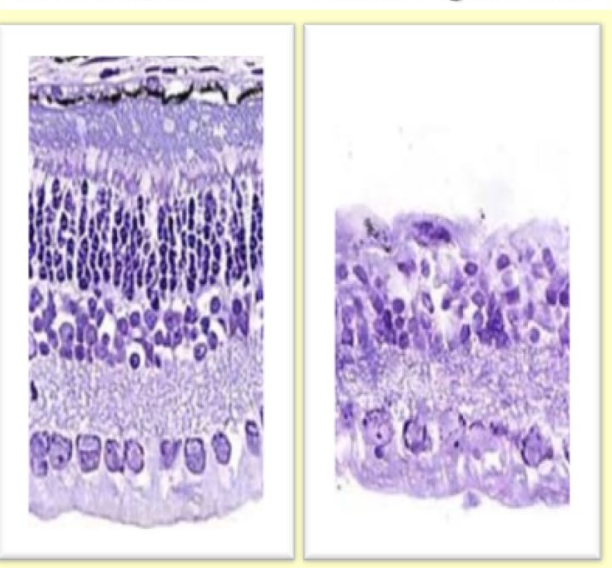

Retinal Degeneration

ganglion cells (GCs, green) of the ganglion cell layer (GCL) whose axons form the optic nerve (green) and project to the brain. Light first strikes these GCs, which in turn contact the feet of Müller glial cells (pink) whose body extends throughout the entire inner retina. Right panels: Histological staining of the retina from a healthy control or a blind animal suffering retinal degeneration and lacking the Photoreceptor cell layer (ONL) whereas the inner retina remains viable (INL and GCL) 
Fig. 2 Action spectra for the photoisomerase retinal $\mathrm{G}$ protein-coupled receptor (RGR) and non-visual opsins Opn5 (neuropsin), Opn4 (melanopsin) and Opn3 (encephalopsin), the Vertebrate Ancient opsin (VA) and the visual opsin rhodopsin (Rh). The graph shows the relative absorbance for the non-visual photopigments RGR, Opn3, Opn4, Opn5, VA opsin, and $\mathrm{Rh}$ peaking in the visible spectra near the UV-blue region ranging from 375 to $525 \mathrm{~nm}$

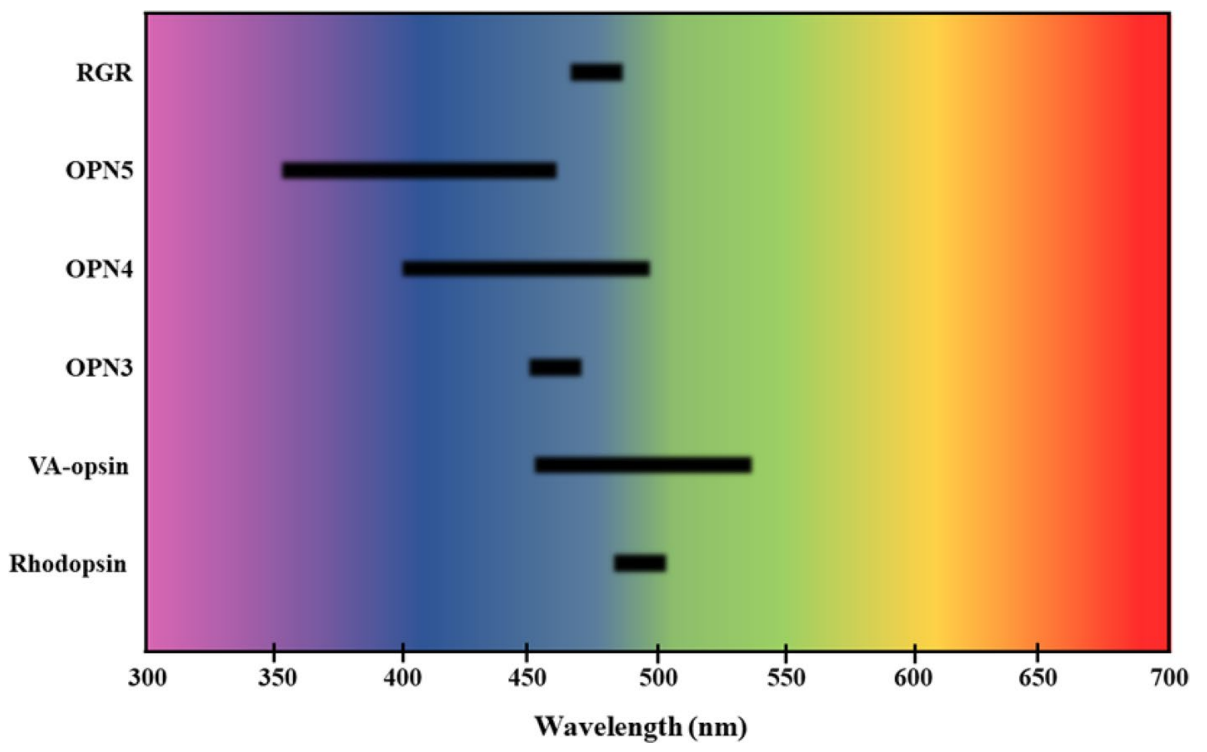

in diurnal (colors) and nocturnal (black and white) vision, respectively (Tessier-Lavigne and Placzek 1991). PRCs have similar functional regions: the outer segment (OS), a region specialized in light detection situated at the distal retina surface and made up of a number of stacked membrane discs containing opsin-pigments subject to constant renewal (shedding); the inner segment, the cellular nucleus involving the biosynthesis machine, and a terminal ending that forms synapses with the target neighbor cells (see Fig. 1). As mentioned above, vertebrate retina contains a variety of photopigments expressed in different cell layers of the outer and inner retina, implicated in distinct image-forming and NIF activities (Fig. 3) (Guido et al. 2010; Tsukamoto and Terakita 2010). In this respect, the pathways related to vision and image formation encode very complex information in terms of color, movement, spatial features (size, shape), contrasts, backgrounds, among others, while the NIF pathway is related to a number of reflex and subconscious activities that depend preferentially on information related to irradiance and duration of photic stimuli (Nelson and Takahashi 1991; Roenneberg and Foster 1997; Devlin and Kay 2001; Yoshimura and Ebihara 1996; Lucas et al. 2001). Nevertheless, under physiological conditions, visual and non-image photoreceptors coexist in the retina and cooperate in photic detection, light synchronization of circadian rhythms, and modulation of other NIF functions.

Study of the evolution of the vertebrate eye and photoreceptors has attracted the attention of researchers for decades and even centuries. The eye was regarded by Charles Darwin as a beautiful example of evolution (Darwin 1859) and by Santiago Ramón y Cajal (Nobel Prize 1906) as "an exquisitely designed and structured organ: a monument to the power of evolution" (Lamb and Collin 2007). Pioneering genetic experiments carried out by Walter Gehring based on the discovery of Pax 6 as the master control gene for the development of this organ in the most varied of species (Gehring and Ikeo 1999; Lamb and Collin 2007) led to the proposal of a monophyletic origin followed by a divergent, parallel, and convergent evolution. Nevertheless, and beyond eye evolution, the assembly of the different types of photoreceptors expressing diverse opsins in a single organ such as the vertebrate retina remains to be elucidated.

\section{From Molecule to Cell}

\section{A Short Tale of Opsin Diversity and Diversification}

Opsins are a monophyletic branch within the heterogenous $\mathrm{G}$ protein-coupled receptor (GPCR) superfamily; to date, more than 1000 opsins have been identified in vertebrate and non-vertebrate species (Santillo et al. 2006; Porter et al. 2011). Although there are still several missing pieces in the evolutionary story of opsin, there are some common landmarks worth highlighting with respect to the two main components of opsin structure: the apoprotein and the chromophore. The first is a single polypeptide chain ranging from 340 to 500 amino acids $(30-60 \mathrm{kDa})$ with the classical seven $\alpha$-helical transmembrane domains, connected by cytoplasmic and extracellular loops. These structural bundles form a hollow cavity on the extracellular side that serves as the binding site for the chromophore, specifically by means of a protonated Schiff base linkage with a highly conserved Lysine residue located at position 296 (in the seventh transmembrane domain) (Peirson et al. 2009). In order to stabilize this positive charge, a counterion is located at the third transmembrane domain, predominantly a glutamate residue that can be placed at position 181 or 113 . 


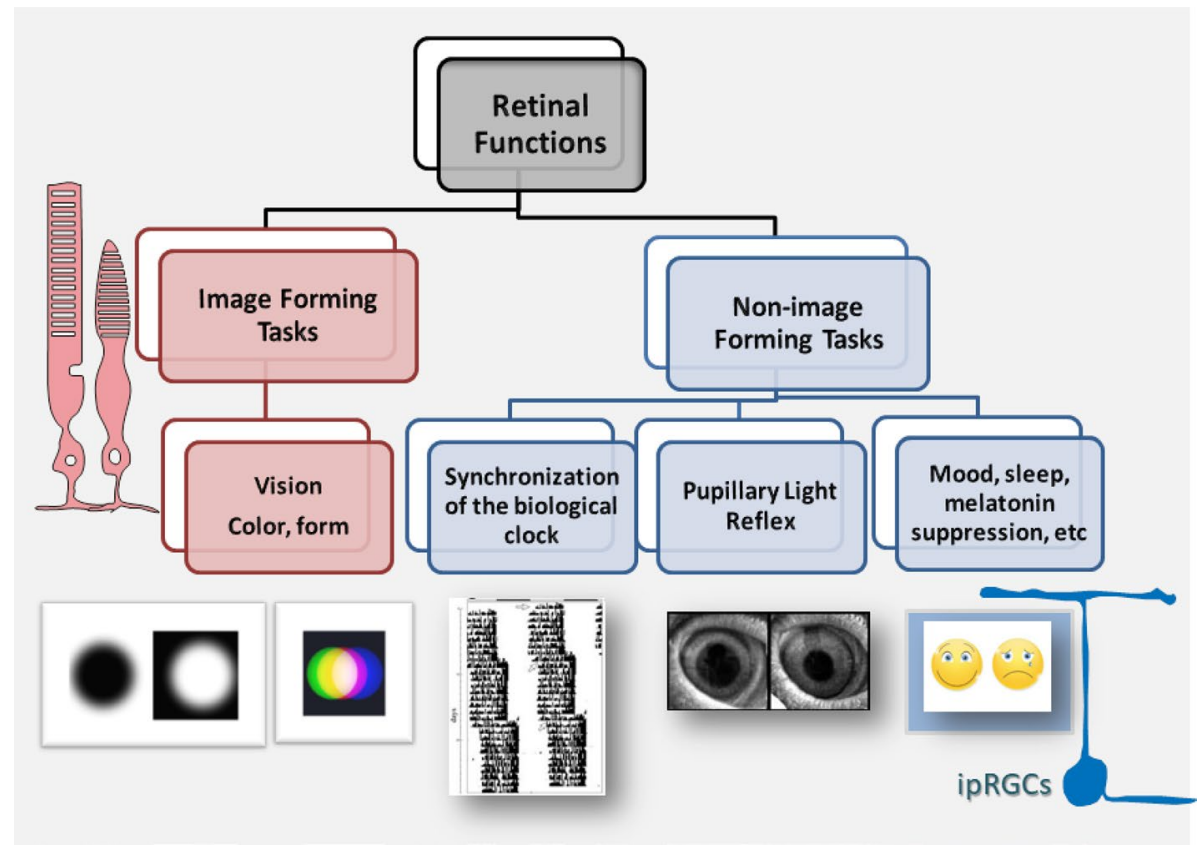

Fig. 3 Visual and non-visual circuits. Retinal functions. Image forming and non-image forming tasks. The visual circuit (pink) includes photoreceptor cells (rods and cones), which is responsible for coordinating the image-forming activities that lead to vision (color, form, size, etc.) through projections from the retina to the brain (visual cortex and other brain areas) allowing us to visualize the surrounding environment. The non-visual circuit (blue) including intrinsically photosensitive retinal ganglion cells (ipRGCs) and other inner retinal cells regulates diverse subconscious and reflex functions such as the synchronization of daily rhythms by light, the pupillary light reflexes, photic inhibition of pineal melatonin, mood, sleep, and other non-visual functions. This circuit projects from the retina to various

Another important and conserved feature of the apoprotein is the presence of glutamate, arginine, and tyrosine residues at positions 134-136, involved in the G protein interaction that transduces the light stimuli into a chemical signal familiar to the cell (Peirson et al. 2009; Shichida and Matsuyama 2009). The chromophore is a vitamin-A based retinaldehyde, subdivided into 4 groups, A1-A4, of which A1 (retinal) and A2 (3-4 dehydroretinal) are found in vertebrates. A1 is the most commonly found chromophore in both vertebrates and invertebrates, whereas A2 is only found in non-mammalian vertebrates such as fish, amphibian, and reptiles (Provencio et al. 1992; Provencio and Foster 1993); its availability and use depend on environmental/seasonal lighting conditions (Shichida and Matsuyama 2009). Among the various isomers, 11-cis-retinal is the most abundant chromophore in darkness, changing its conformation to an all-trans-form after photon incidence (Shichida and Matsuyama 2009). This conformational change promotes a pivotal movement of helix VI in the apoprotein, thereby activating a downstream G protein cascade (Tsukamoto and Terakita 2010). Interestingly, 11-cis-retinal alone has a particular absorbance brain areas regulating the physiology and behavior of vertebrates. Intrinsic photosensitivity persists even in blind animals. In GUCY1 * chickens that are blind from birth, light still regulates the feeding rhythms (double plot actogram shown below) and the pupillary light reflex (image of a GUCY $1 *$ chicken pupil before and after light stimulation). In the inner retina of vertebrates, light is detected through ipRGCs that project to the brain areas forming a non-visual circuit, independent of image-forming activities, which in non-mammalian vertebrates is further supplemented by photosensitive HCs and Müller glial cells expressing Opn4, Opn3 or Opn5, and RGR. See text for further details

peak $(380 \mathrm{~nm})$ and responsiveness capacity that are modified in the context of the opsin. Thus, throughout the opsin family, the presence of retinal increases photoisomerization efficiency and spectral tuning to light sensing over a broad spectrum of wavelengths (Shichida and Matsuyama 2009; Porter et al. 2011).

The replacement of 11-cis-3,4-didehydroretinal by 11-cisretinal along evolution shifts the absorbance spectrum of the resulting new photopigment toward longer wavelengths. It is noteworthy that in GUCY 1 *chickens, totally blind since hatching due to mutation of the guanylate cyclase (GC) 1 gene, with complete loss of rods and cones and exhibiting no electrical responses to light (Valdez et al. 2009), the action spectrum for PLRs revealed that the light responses were mediated by a vitamin A2-based opsin with higher absorbance at $484 \mathrm{~nm}$, resembling an Opn4-like photopigment (Valdez et al. 2009).

The identification of visual and non-visual opsins in vertebrates and non-vertebrates supports the hypothesis that opsin diversification took place early in evolution, before the deuterostome/protostome split (Terakita 2005). The 
first evolutionary step of this process in the early metazoans is considered to be gene duplication from a GPCR of the A family, closely related to melatonin receptors (Shichida and Matsuyama 2009; Lamb 2013). This ancestor used retinal as a ligand, but it was not until the divergence of eumetazoans and the appearance of the lysine residue in position 296 that covalent bonding between the ligand and the receptor occurred, thus forming a single light-sensing molecule, marking the appearance of the lysine residue (Shichida and Matsuyama 2009; Lamb 2013). At first, this linkage might not have been protonated, and therefore, the opsin would have been UV absorbing, until the appearance of a negatively charged residue in at position 181, acting as a counterion, and allowing light absorption in the visible spectrum and photo-reversion to the active state (Lamb 2013). From this point up to bilaterian diversification, two gene duplications would have taken place in a very short period of evolutionary time. The first one gave rise to opsin attachment to different membrane types such as intracellular organelles or surface membranes and is the ancestor for the photoisomerase lineage. The second group underwent a second gene duplication, giving rise to the well-known C-type (ciliary type) and R-Type (rhabdomeric type) opsins (Lamb 2013). Based on this classification, there are three main opsin lineages: deuterostomes, protostomes, and cnidarians, cnidarian opsins appearing as orthologs (Lamb 2013). However, based on insertion/deletion events and intron arrangement, other authors sustain that there are 4 initial opsin lineages: 1-Cnidops, 2-C- type opsin, 3-R-type opsin, and 4- Group 4 opsin (which includes neuropsins, peropsins, and photoisomerases) (Porter et al. 2011). As opposed to the above mentioned theory, under this classification, there is closer evolutionary proximity between groups 1 and 2, and between 3 and 4 (Porter et al. 2011). Nevertheless, the Cnidops clade is restricted to cnidarian opsins, whereas the other three clades gave rise to the broad spectrum of vertebrate and invertebrate opsins (Porter et al. 2011). Consequently, vertebrate visual and non-visual opsin lineages can be lined up with three ancestral genes: C-type, R-type, and group 4 opsins (also named retinal pigment epithelium -RPE- opsins) (Scheme 1) (Bellingham et al. 2003; Porter et al. 2011; Lamb 2013). A number of families have been described based on different characteristics: type of $\mathrm{G}$ protein coupling, molecular evolution, sequence homology, amino acid alignment, insertion/deletion events, and/ or intron arrangement (Terakita 2005; Santillo et al. 2006; Peirson et al. 2009; Shichida and Matsuyama 2009; Porter et al. 2011; Beaudry et al. 2017). From an evolutionary point of view, we will discuss the main characteristics of three ancestral lineages and the main opsin groups they include.

C-type opsins diverge with two main characteristics: $G$ transducin $\left(G_{t}\right)$ protein coupling and counterion position displacement (Shichida and Matsuyama 2009; Porter et al.
2011). Through transducin activity, this type of opsin activates an intracellular cascade that modifies cyclic nucleotides levels and controls membrane-gated channels, most commonly to drive cell hyperpolarization (Koyanagi and Terakita 2014; Terakita and Nagata 2014). Moreover, the counterion relocalization at residue 113 modifies opsins' photochemical properties and confers instability on the isomerized retinal photoproduct; upon photon incidence, the all-trans-retinal is released and the opsin "bleaches," a characteristic known as monostability (Tsukamoto and Terakita 2010). C-type opsins are the most diverse group and include all vertebrate visual opsins and some vertebrate non-visual opsins. The main visual opsins are rod and cone opsins (Opn2 and Opn1, respectively), although as mentioned above (Peirson et al. 2009; Shichida and Matsuyama 2009), this latter group is further subdivided according to wavelength sensitivity (LWS, MWS, SWS1, and SWS2 opsins). Moreover, C-type opsins include several different non-visual opsin families, mainly present in non-mammalian vertebrates: (1) the pineal opsins (pinopsin, parapinopsin, and parietopsin) which are extra-ocular opsins located in brain structures of fish, amphibia, reptiles, and birds (as these opsins are expressed in extra-retinal tissues were not included in the present review); (2) the vertebrate ancient (VA) opsins that show a great number of variants among fish, particularly (but not restricted to) teleosts; and (3) the TMT/Opn3 opsins group which, given their shared photochemical characteristics and wide distribution in the body, belongs to the same clade; however, TMT has been isolated from fish, whereas Opn3 is expressed in birds and mammals (Peirson et al. 2009; Shichida and Matsuyama 2009; Davies et al. 2010; Rios et al. 2019) (Scheme 1).

Since the discovery of Opn4 the R-type opsins clade was included as part of the vertebrate opsin evolutionary tree. This family is under constant revision as Opn4 orthologs continue to be isolated in a wide range of species of chordate lineage (Davies et al. 2010). They share the main characteristics of the rhabdomeric photoreceptor group as they couple to Gq protein to activate a phospholipase C (PLC)-mediated intracellular cascade, ultimately causing cell depolarization (Contín et al. 2006, 2010; Peirson et al. 2009; Shichida and Matsuyama 2009; Davies et al. 2010; Morera et al. 2016), and maintain the counterion position at residue 181 . This latter characteristic confers bistability on melanopsin, as the photoproduct after isomerization is stable and can be further activated by a shorter long-wave photon (Scheme 1). However, this type of opsin shows lower $\mathrm{G}$ protein activation efficiency (Tsukamoto and Terakita 2010). Opn4 identification became one of the most important discoveries in the field of chronobiology and circadian entrainment and is further discussed in the following sections.

Finally, the group 4/RPE opsins are considered a mixed group of opsins expressed in the RPE and including RGR 


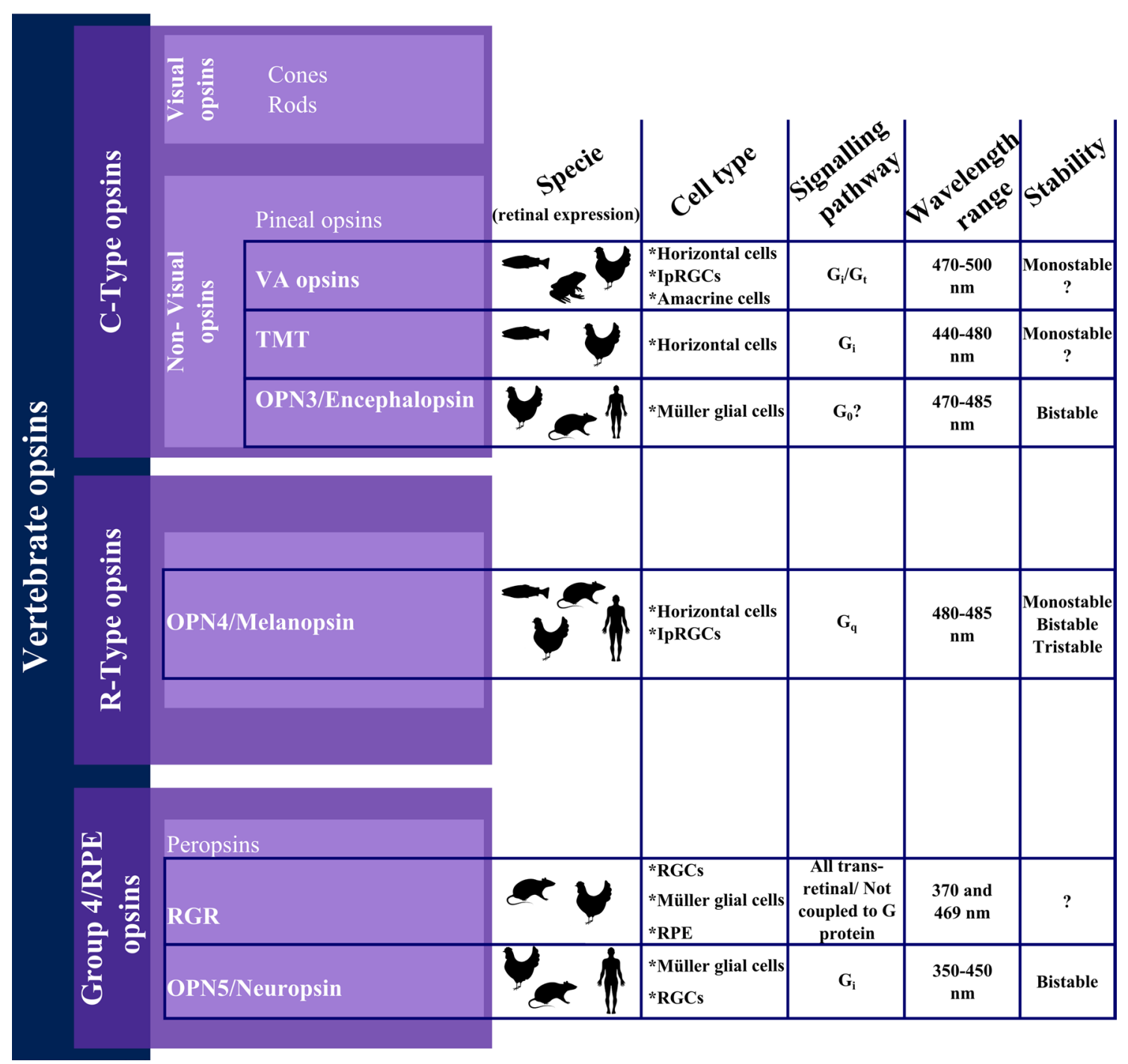

Scheme 1 Vertebrate Opsins: C-type Opsins are ciliary-type opsins comprising Visual and Non-Visual Opsins (pineal opsin, Vertebrate Ancient Opsin (VA) and TMT/Opn3 (encephalopsin). Visual opsins include short, medium and long wavelength opsins (Opn1) and rhodopsin (Opn2) present in the outer segments of cones and rods (visual photoreceptor cells) and involved in day and night vision, respectively. Non-Visual Opsins include opsins that use retinal as a chromophore and bind to G protein: VA, TMT and Opn3 (encephalopsin). Opn3 is expressed in neurons of the inner retina and in Müller glial cells through cascades and functions not yet fully elucidated. The chromophore 11-cis-retinal (vitamin A derivative) is bound to a lysine residue in the protein part of the photopigment. Upon light stimulation, 11-cis-retinal is photoisomerized to all-trans retinal. Opsins are coupled to a $G$ protein that acts as the light transducer. Gi: inhibitory $\mathrm{G}$ protein, Gt: transducin, $\mathrm{Gq}$; $\mathrm{Gq}$ protein. R-type Opsins are rhabdomeric-type opsins and include Opn4 (melanopsin). Through evolution, vertebrates have conserved 2 Opn4 genes (Opn4m

and peropsin. RGR may function as an all-trans-retinal photoisomerase; the isomerized 11-cis-retinal does not dissociate from RGR and, therefore, does not contribute significantly to the pool of 11-cis-retinal, acting perhaps as an and Opn4x). Opn4x has been lost in mammals along with other opsins, likely during the mammalian entry into the nocturnal phase. Non-mammalian vertebrates (birds, fish, etc.) possess both Opn4 genes (Opn4m and Opn4x) which encode for the corresponding proteins and isoforms differentially expressed in ipRGCs and horizontal cells of the inner retina. The phototransduction cascade triggered by Opn4 activation involves the Gq protein, phospholipase C (PLC) activation, $\mathrm{Ca}^{2+}$ mobilization, and membrane depolarization with GABA release in the inner retina. Group 4/RPE Opsins include the photoisomerases peropsin and RGR and Opn5 (neuropsin). Peropsin and RGR bind all-trans retinal and are expressed in the retina of vertebrates, mainly in the retinal pigment epithelium (RPE). RGR is also expressed in inner retinal cells and Müller glial cells and involved in recycling the chromophore required to constitute an active photopigment in ipRGCs. Opn5 is expressed in inner retinal cells and Müller glial cells and responds to violet light. See text for further detail

opsin that does not couple to a $\mathrm{G}$ protein (Peirson et al. 2009; Shichida and Matsuyama 2009). Peropsins also work as photoisomerases but contain sequence motifs conserved among family-A GPCRs which are important for the activation of 
the $\mathrm{G}$ protein, suggesting that they might bind and activate a $\mathrm{G}$ protein; however, the physiological significance of this is as yet unclear (Peirson et al. 2009; Shichida and Matsuyama 2009). This family is proposed to include one last type of opsins-neuropsins or Opn5-that have intron positions conserved in the photoisomerases (Peirson et al. 2009; Shichida and Matsuyama 2009; Beaudry et al. 2017). This type of opsins has been isolated from neural tissues and is widely present among fish clades as well as in birds and mammals (Porter et al. 2011; Beaudry et al. 2017; Rios et al. 2019). Even though this group has not been fully characterized, there is evidence pointing to its capacity to absorb light in the UV range and to show bistability capacity, except for mammalians forms (Yamashita et al. 2014) (Scheme 1). Thus, as new opsins are identified, they tend to be included in already existing groups; nevertheless it should be taken in consideration that there can be exceptions, since there is no strict association between evolutionary group and cell type or tissue expression, $\mathrm{G}$ protein coupling, counterion position, and mono- or bistability (Davies et al. 2010; Tsukamoto and Terakita 2010; Porter et al. 2011; Sakai et al. 2015).

The question remains, why have so many opsins emerged and been retained over the course of evolution?

The first point to be considered is the existence of visual and non-visual opsins to discriminate essential and vital functions in image formation and NIF activities (reflex and subconscious activities). The diversity of visual opsins explained by different wavelength sensitivities together with the influence of environmental lighting conditions would seem consistent with the intricate function of image forming under different lighting conditions. Nevertheless, the process of sensing light irradiation associated with NIF tasks is by no means a trivial task, justifying the retention of nonvisual opsins along evolution (Peirson et al. 2009; Davies et al. 2010). In this respect, sensing the time of day relies on detecting the quality of light, given that the amount, spectral composition, and source of light changes systematically as the day advances (Peirson et al. 2009). Interestingly, a conserved feature of these opsins is their wavelength sensitivity around $480 \mathrm{~nm}$ (with higher energy), probably related to the efficacy and penetrance of light in reaching deep brain structures and also reflecting the spectral composition of light at twilight. The relevance of the light spectrum that reaches organisms living at great aquatic depths and drives opsin diversification is clearly exemplified in the complex evolutionary tuning of rod sensitivity in deep-sea fish, which develop in photon-limited dim-light environments and bioluminescence in the blue (Hunt et al. 2001). The other important aspect to consider in evolution is the diverse types of structures that express non-visual opsins, originally proposed as vestigial organs retained by lower vertebrates and lost in mammals (Peirson et al. 2009; Davies et al. 2010; Beaudry et al. 2017). In view of the level of complexity of irradiance sensing, this initial idea has changed over time, and non-visual opsins are now understood as part of a vital process supporting the existence of extra-ocular organs specifically designed for this task (Davies et al. 2010). Moreover, the broad repertory of non-visual opsins and extra-ocular structures in fish and amphibians has been proposed to play a vital role in development and/or oxidative damage in translucent larvae (Beaudry et al. 2017). These two functions would explain why non-visual opsins in birds are present in different retinal cell populations within the eye (Contín et al. 2006; Verra et al. 2011; Morera et al. 2016; Díaz et al. 2017; Rios et al. 2019) and brain structures, as bird development takes place in a darker environment-the egg-, whereas in mammalians, they are restricted to a RGC subpopulation (Provencio et al. 2000; Berson et al. 2002; Hattar et al. 2002; Davies et al. 2010; Beaudry et al. 2017). These findings can likely be explained by the "nocturnal bottleneck" theory in which mammals lost their extra-ocular photo-sensing organs when they were forced to move to nocturnal niches where these photoreceptors would have been insufficient to sense light under twilight and darkness conditions (Gerkema et al. 2013).

\section{Inner Retinal Photoreceptors: The Intrinsically Photosensitive RGCs}

Beyond the classical definition of the "eye" as simply "the organ of sight," another very important role of this organ has emerged in recent decades: the eye can act as an ambient light detector even under some conditions of blindness. A number of NIF functions such as daily adjustment of biological clocks to the changing environmental conditions, light-inhibition of activity and masking, acute suppression of melatonin synthesis in the pineal gland, and PLRs are still found in animals suffering some types of blindness as the result of mutations causing severe retinal degeneration (RD) of classical visual PRCs (Foster et al. 1991; Freedman et al. 1999; Lucas et al. 1999; Foster and Hankins 2002; Van Gelder et al. 2003) (Fig. 3). Clyde Keeler reported in 1927 that a blind rodless mouse retained its PLRs (Keeler 1927); however, in the eighties, Ebihara's lab found that similar blind rodents were still capable of entraining their locomotor activity rhythms to the light-dark (LD) cycle (Ebihara and Tsuji 1980; Yoshimura and Ebihara 1996); and in the nineties, Russel Foster's group published a number of pioneering reports shedding light on the photoreceptors involved in mammalian photoentrainment using different RD models with complete loss of rods and progressive decrease in cones (Foster et al. 1991; Freedman et al. 1999; Lucas et al. 1999, 2001; Foster and Hankins 2002; Van Gelder et al. 2003). These observations strongly suggest that even though eyes are absolutely essential for the photic regulation 
of the circadian rhythmicity (Nelson and Takahashi 1991), they do not function through a rod/cone mechanism. In fact, the genetic ablation of visual photoreceptors has no effect on the phase-shifting effects of light on circadian responses and acute pineal melatonin suppression (Foster et al. 1991; Provencio et al. 1998; Freedman et al. 1999; Lucas et al. 1999; Hankins et al. 2008; Peirson et al. 2009); however, circadian photoresponses and PLRs are lost in RGC-deficient animals. Indeed, these latter light responses were triggered by inner retinal photoreceptor cells localized in a subset of mammalian RGCs, the so-called intrinsically photosensitive RGCs (ipRGCs) (Fig. 4) (Berson et al. 2002; Hattar et al. 2002, 2003). These cells expressed Opn4 as previously characterized by I. Provencio et al. (Provencio et al. 2000) and were shown to be responsible for conferring photosensitivity on non-retinal cells (Melyan et al. 2005; Qiu et al. 2005). This body of evidence revolutionized the field and provided a very concise neurobiological base for non-visual phototransduction. The mentioned ipRGCs were shown to be responsible for transmitting photic information regarding ambient illumination conditions to brain regions implicated in irradiance detection, blue light detection, responses to long-lasting exposure, and various light-regulated activities mainly associated with NIF tasks (Moore 1995; Zeitzer et al. 2000; Berson et al. 2002; Hattar et al. 2002; Provencio et al. 2002; Hannibal et al. 2004; Wee and Van Gelder 2004), even regulating mood and learning (Fernandez et al. 2018), but also involved somehow in visual processing activities (Sonoda et al. 2018; Sondereker et al. 2020). In non-mammalian vertebrates, blind GUCY1*chickens still responded to light through their inner retinas in order to regulate the different NIF tasks examined (Valdez et al. 2009, 2013). In fact, white or blue light precisely entrained the feeding rhythms of GUCY $1 *$ chickens subjected to different LD cycles and triggered PLRs displaying a significant daily variation with increased sensitivity at midday (Valdez et al. 2015).

\section{Melanopsin (Opn4), Different Isoforms for Distinct Functions}

Opn4 was named melanopsin since it was first identified in the photosensitive dermal melanophores of Xenopus laevis (Provencio et al. 1998, 2000); however, it was found in a broad variety of non-mammalian and mammalian vertebrates including humans and we now know that it is the nonvisual photopigment responsible for a number of NIF tasks

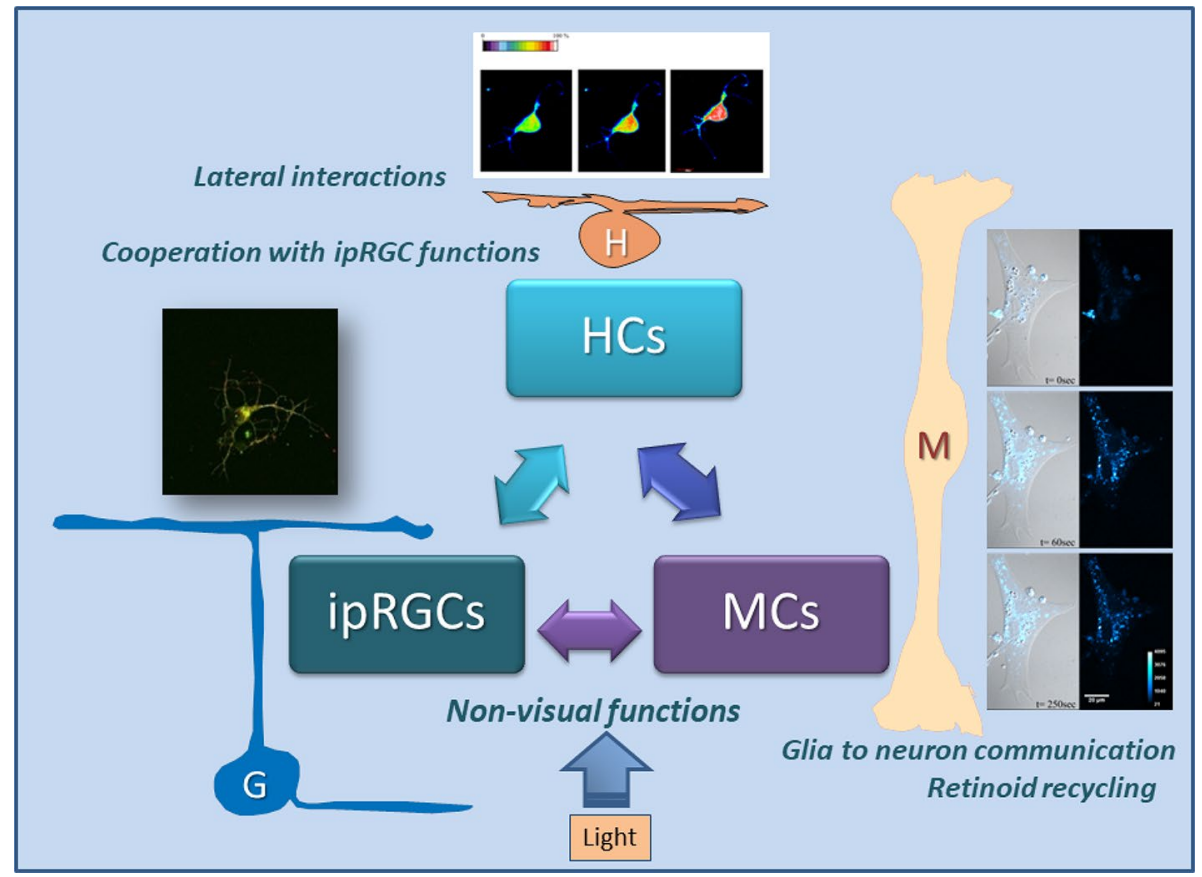

Fig. 4 Non-visual photoreceptors and photo-detectors. The inner retina of non-mammalian vertebrates contain diverse intrinsically photosensitive neuronal cells (intrinsically photosensitive retinal ganglion cells-ipRGCs-, and horizontal cells-HCs-) and Müller glial cells (MCs) that made up a network for light detection mainly in the blue region of the visible spectra. Opn 4 proteins $(\mathrm{Opn} 4 \mathrm{~m}$ or Opn $4 \mathrm{x}$ ) are expressed in ipRGCs and HCs conferring intrinsic photosensitiv- ity to these cells, whereas inner retinal neurons and MCs expressing Opn3, Opn5, and RGR respond to blue light that ultimately triggers $\mathrm{Ca}^{2+}$ intracellular mobilization. ipRGCs control different non-imageforming (NIF) activities together with HCs that mediate lateral interactions with visual cells and may cooperate with ipRGCs in regulating NIF activities, whereas MCs regulate cell-to-cell interactions and retinoid recycling upon light exposure. See text for further details 
triggered by light. Based on amino acid sequence and other molecular characteristics, Opn4 displays higher homology sequence with invertebrate rhodopsins, than with vertebrate visual opsins associated with Gi-protein transducin. In fact, Opn4 shares a close phylogenetic relationship with invertebrate opsins, both groups belonging to the Gq-coupled subfamily of opsins (Provencio et al. 1998; Koyanagi and Terakita 2008). Solid proof that Opn4 is indeed such a nonvisual opsin involved in these NIF tasks came from a number of studies detailed as follows: (i) Opn4 knockout mice showed that this opsin acts as the photosensitive molecule involved in PLRs, photic-entrainment of activity rhythm and melatonin suppression in the pineal gland (Hattar et al. 2003; Lucas et al. 2003; Raible et al. 2006); (ii) ectopic expression of Opn4 restores photosensitivity in blind mice (Panda et al. 2003) and (iii) transient heterologous Opn4 expression in immortalized cultures of non-retinal cell lines renders these cells light-responsive (Melyan et al. 2005; Qiu et al. 2005; Lin et al. 2008). Furthermore, Opn 4 expression in primate and mice retinas can also modulate visual processing related to the fine tuning of visual pathways at certain times of day (Dacey et al. 2005). A further piece of evidence in support of a possible involvement of Opn4 in vision is that a variety of different Opn4 (+) RGCs subtypes with diverse morphology project to specific brain areas and to all major retinorecipient regions (Barnard et al. 2006; Berson et al. 2010; Brown et al. 2010; Ecker et al. 2010; Schmidt et al. 2011). These projections likely contribute to spatial visual perception in mice (Sonoda et al. 2018), and their influence may extend to the regulation of environmentally related visual information useful for multiple visual processing (Badea et al. 2009). In addition, amacrine cells and bipolar cells transmit inputs to ipRGC neurites, thereby, providing an anatomical base by which ipRGCs may modulate visual pathways (Schmidt and Kofuji 2009) and Opn4 appears to be involved in modulation of the cone visual pathway in humans in response to light exposures of long duration (Lucas 2013). Moreover, Opn4 (+) RGCs in primates (closely related to ipRGCs in rodents) combine with visual PRC mechanisms to encode irradiance over the whole visual spectrum range (Dacey et al. 2005).

According to nocturnal bottleneck theory (Gerkema et al. 2013), along evolution most mammals acquired nocturnal habits by entering the nocturnal niche and consequently losing some visual opsins and Opn4 isoforms $(\mathrm{Opn} 4 \mathrm{x})$, likely as a consequence of a chromosome rearrangement (Bellingham et al. 2006). Opn4 is a highly conserved opsin through evolution and was found even in amphioxus and sea urchins, demonstrating that deuterostomes have a Opn4 gene(s) (Koyanagi and Terakita 2008). In this connection, in most non-mammalian vertebrates, there are at least two kinds of Opn4, classified into two groups within the phylogenetic tree: Opn4x, the Xenopus ortholog gene and Opn $4 \mathrm{~m}$, the mammalian gene
(Bellingham et al. 2006). Although non-mammalian vertebrates express both Opn $4 \mathrm{~m}$ and $\mathrm{x}$, mammals retain the expression of Opn4m only. The physiological roles played by these two Opn4s in non-mammalian vertebrates require further investigation. Most studies involving Opn4 expression in cultured cells to elucidate its molecular properties showed that this photopigment constitutes a blue-sensitive opsin with a maximum absorption at $485 \mathrm{~nm}$ (Koyanagi et al. 2005), a bistable nature and a light-mediated activation mediated by a $\mathrm{Gq}$ protein with an efficiency rate similar to that of Gq-coupled visual pigments of invertebrates (Terakita et al. 2008). Moreover, this report showed that amphioxus Opn4 colocalized with the Gq protein in photoreceptor cells (Provencio et al. 1998; Koyanagi and Terakita 2008) displaying a clear depolarization in response to light, like invertebrate rhabdomeric photoreceptor cells. Two Opn4s were described in cyclostomes (Sun et al. 2014). In fact, lamprey and hagfish express the mRNA encoding for an Opn4 protein belonging to the Opn4m group (mammalian orthologs). Lamprey Opn4 is a functional photopigment with a maximum absorption at $480 \mathrm{~nm}$. In addition, Zebrafish express five genes for Opn4 (Koyanagi et al. 2005), three corresponding to Opn4m (Opn4m-1, Opn4m-2 and Opn4m-3) and the other two to Opn4x (Opn4x-1 and Opn4x-2). Opn4m and $x$ are widely expressed in zebrafish retina and other organs, and all the mentioned Opn4s were functional when expressed in the Neuro 2A cell line. However, in another series of studies, three of five Opn4s were not functional when the chromophore provided was all-trans-retinal, a behavior typical of monostable opsins like ciliary opsins. In addition, the cartilaginous fish (Chondrichthyes) expresses three Opn4 genes (Koyanagi et al. 2005).

Focusing in particular on the retina of non-mammalian vertebrates, we and other laboratories have demonstrated that the two Opn4s (Opn4x and Opn4m) are expressed at the level of mRNA (Bailey and Cassone 2005; Contín et al. 2006; Tomonari et al. 2007; Valdez et al. 2009) and protein (Contín et al. 2010; Verra et al. 2011; Díaz et al. 2014). During development, the expression of Opn4 proteins appears to vary dramatically in different cell populations and layers of the chicken retina (Verra et al. 2011) (Fig. 5). In fact, Opn4m was shown to be expressed only in the GCL throughout development, whereas Opn4x was firstly confined to the formation of GCL, axonal fibers and optic nerve during early development at embryonic day (E8), though by E15, its expression also appeared in the lower OPL, colocalizing with Prox 1, the main marker for horizontal cells (Fig. 5) (Verra et al 2011). Horizontal cell birth and migration take place between E10-15, when Opn4x-associated immunoreactivity strongly appeared in the cell somas of Prox1 (+) horizontal cells with Opn4x (+) cells bearing a morphological similarity to typical horizontal cells such 


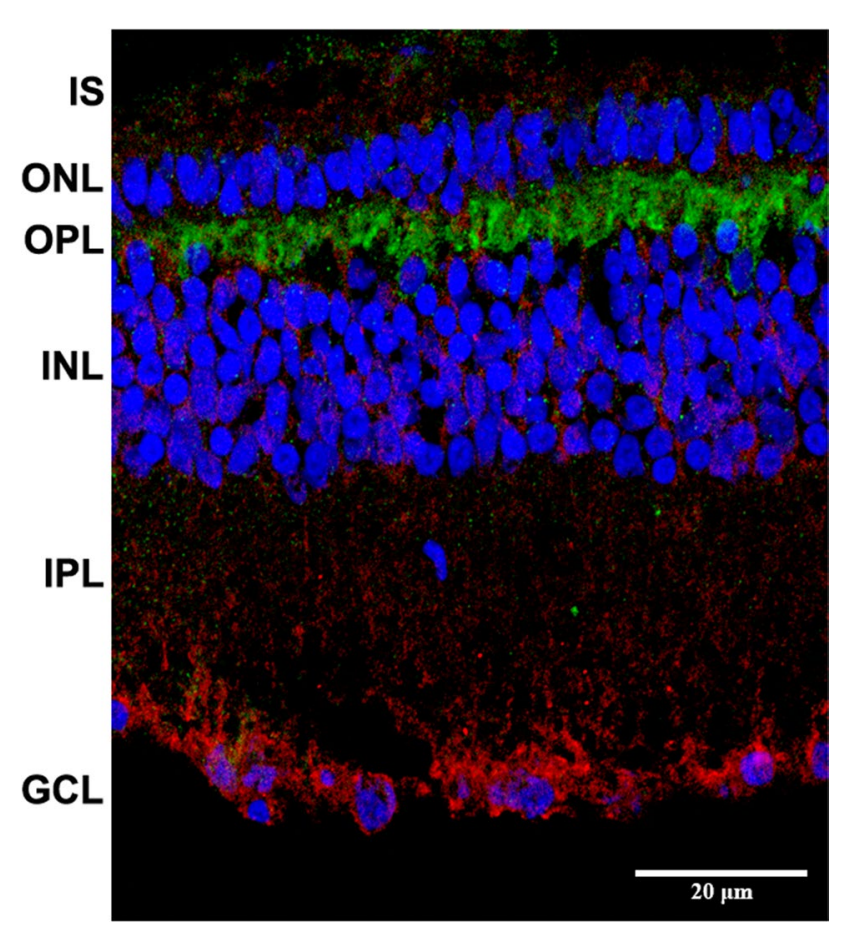

Fig. 5 Immunochemistry for non-visual opsins Opn4x and Opn4mlike proteins in the chicken retina at postnatal day 10 (P10). Retinal sections were immunolabeled for Opn4m (red), Opn4x (green), and DAPI (blue, nuclear staining) visualized with specific primary antibodies by confocal microscopy and $40 \mathrm{X}$ of magnification. Positive immunoreactivity was visualized for Opn4m in cell somas of the GCL and traces in the IPL and INL at P10 as previously shown by Verra et al (2011). Positive immunoreactivity for Opn4x was visualized mainly in the IPL at P10. Scale bar $=20 \mu \mathrm{m}$. $I S$ inner segment, $O P L$ outer plexiform layer, $O N L$ outer nuclear layer, $I N L$ inner nuclear layer, $I P L$ inner plexiform layer, $G C L$ ganglion cell layer

as axonless candelabrum-shaped cells (Verra et al. 2011), shown to mainly contact cone pedicles (Araki and Kimura 1991; Poché and Reese 2009).

We reported for the first time the biochemical nature of the phototransduction cascade taking place in ipRGCs of any vertebrate expressing different isoforms of Opn4 (Contín et al. 2006, 2010; Díaz et al. 2014, 2016) and later for the Opn4x-expressing horizontal cells in primary cultures from developing chicken retina (Morera et al. 2016). This depolarizing cascade in ipRGCs involves Opn4 as the photopigment coupled to a Gq protein and retinaldehyde as chromophore, activation of a PLC as effector, increasing levels of $\mathrm{IP}_{3}$ and other inositol-phosphates, and consequent $\mathrm{Ca}^{2+}$ mobilization through the opening of transient receptor potential channels (TRPC) (Fig. 6) (Contín et al. 2006, 2010; Díaz et al. 2014, 2016). Later studies clearly confirmed that upon light stimulation, photoproducts activate the Gq-type $\mathrm{G}$ protein, stimulating in turn the activity of membrane PLC, likely a PLC $B$ isoform; this generates an increase in $\mathrm{IP}_{3}$ and DAG levels and release of $\mathrm{Ca}^{2+}$ from internal and external stores such as
TRPC, ultimately leading to photoreceptor cell membrane depolarization (Fig. 6) (Yarfitz and Hurley 1994; Yau and Hardie 2009; Do 2019) as mentioned above in ipRGCs and horizontal cells of birds (Contín et al. 2006, 2010; Díaz et al. 2014; Morera et al. 2016). In addition, a recent report showed that the different mouse ipRGC subtypes rely on a ciliary phototransduction mechanism involving cyclic nucleotide as the second messenger and hyperpolarizationactivated and cyclic nucleotide-gated channels (Jiang et al. 2018). Both rhabdomeric and ciliary-like mechanisms could operate in ipRGCs of mammals in response to light, revealing a complex heterogeneity in phototransduction among ipRGCs.

\section{Lost Along the Way: Intrinsically Photosensitive Horizontal Cells, from Teleost to Mammals}

As mentioned above (Contín et al. 2006, 2010; Díaz et al. 2014, 2016; Verra et al. 2011), in addition to their presence in mammals and other vertebrates, ipRGCs expressing different isoforms of Opn4 were also found in early development chicken retina (Fig. 5). Strikingly, Opn4x was also strongly expressed in horizontal cells at later developmental stages (Verra et al. 2011; Morera et al. 2016), conferring intrinsic photosensitivity on these horizontal cells (Morera et al. 2016) (Fig. 4). The question as to why and to what end horizontal cells in non-mammalian vertebrates are photosensitive remains unanswered. Nevertheless, we can hypothesize some answers based on published findings. Inhibitory neurons comprise only $10-20 \%$ of the total neural population, their connectivity, and recruitment being essential in cognition, movement, and sensation. In the retina, horizontal cells project laterally and integrate inputs from visual photoreceptor rods and cones, providing them with negative and positive feedbacks to generate an antagonistic, and to a lesser degree agonistic, center-surround receptive field (Diamond 2017). Thus, inhibition is an essential mechanism in maintaining balanced retinal activity. Both Opn4 orthologs (Opn4m and $\mathrm{x}$ ) are widely expressed in zebrafish retina and other organs, and all the mentioned Opn4s are functional when expressed in the Neuro $2 \mathrm{~A}$ cell line.

In addition to their typical role in retinal circuits, horizontal cells in non-mammalian vertebrates may conserve vestiges of ancient photoreceptor cells. In this respect, it was shown that horizontal cells of teleosts were photosensitive independently of rods and cones (Jenkins et al. 2003); this finding was confirmed by Cheng et al. (2009). As mammals entered the nocturnal niche throughout evolution, they lost Opn4x (Bellingham et al. 2006). The physiological roles played by these two Opn4s in non-mammalian vertebrates remain to be fully determined. 


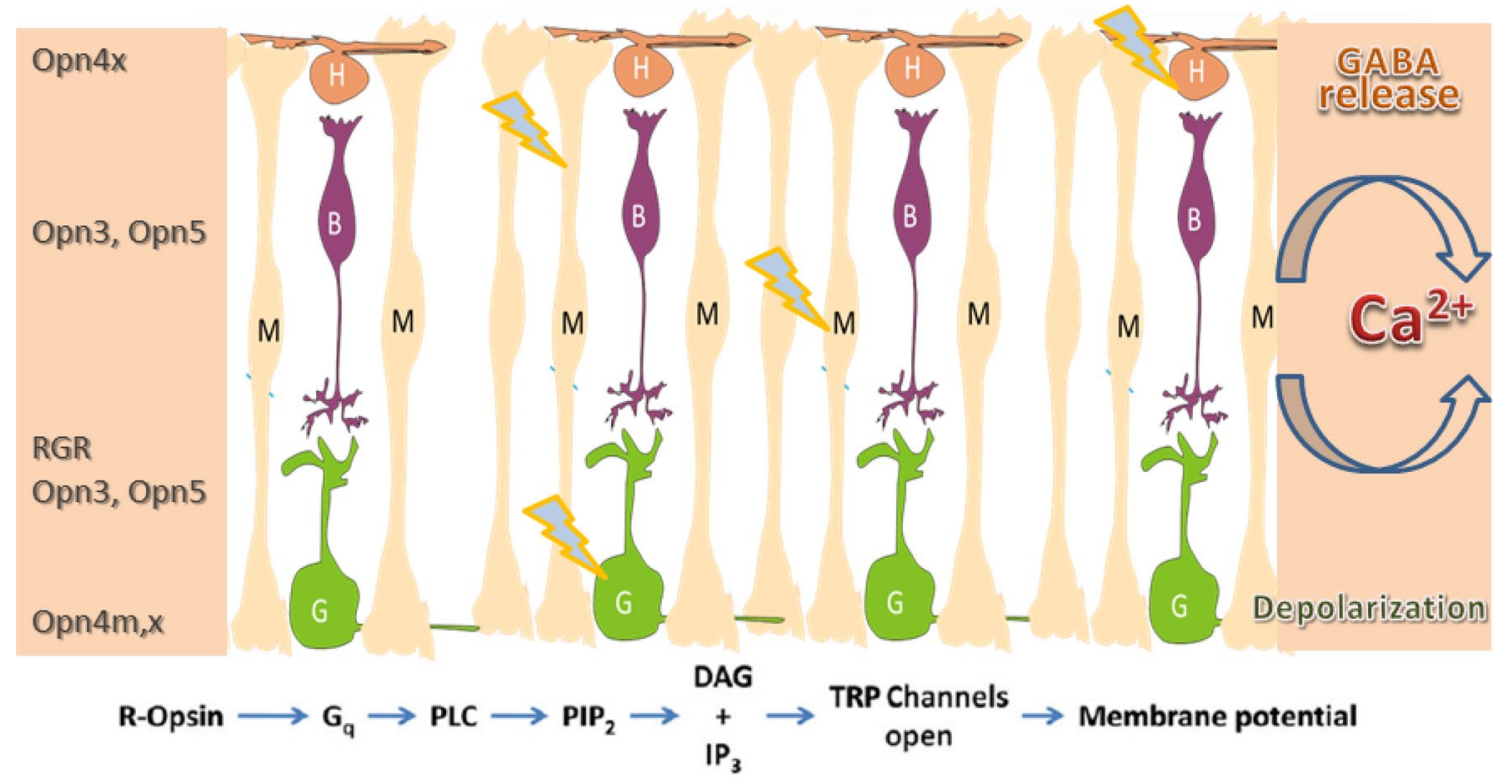

\section{Retinal} Activation

\section{Signal amplification Phototransduction}

\section{Current increase Depolarization}

Fig. 6 Non-visual photoreceptors in the inner retina of vertebrates (bottom panel). The scheme shows the inner retina comprising interneurons such as horizontal cells $(\mathrm{H}$, brown) and bipolar cells, (B, violet) in the inner nuclear layer which connect with retinal ganglion cells $(\mathrm{G}$, green) and Müller glial cells (M, pink). Intrinsically photosensitive $\mathrm{G}$ cells (ipRGCs), $\mathrm{H}$ cells (HCs) and $\mathrm{M}$ cells (MCs) include non-visual photoreceptors/photo-detectors expressing diverse photopigments and photoisomerases. Non-Visual Opsins use retinal as a chromophore and are coupled to a $G$ protein. These opsins include encephalopsin (Opn3), melanopsin (Opn4), and neuropsin (Opn5). They respond to blue light (Opn3 and Opn4) and UV (Opn5) and are involved in the regulation of various light-driven non-visual functions. Photoisomerases RGR and others are expressed in RGCs and MCs in the inner retina to regenerate retinoids in light and provide cells with an active photopigment. Phototransduction cascade

Neuronal networks consist of different types of neurons each with a specific role in maintaining proper network functioning. It has been proposed that changes in the relative strength or participation of excitatory and inhibitory neurons might play a role in regulating the flow of information through the network (Bono and Clopath 2019).

In this sense, we reported in a pioneering work that avian retinal inhibitory neurons (horizontal cells) expressing Opn $4 \mathrm{x}$ mRNA and protein, and components of the non-visual photocascade such as the Gq protein, displayed intrinsic photosensitivity (Morera et al. 2016). Photic responses mainly triggered by blue light elicited a novel phototransduction cascade involving the expression of Opn $4 \mathrm{x}$ and retinaldehyde as photopigment and chromophore, respectively. This $\mathrm{Gq}$ protein photocascade further activates PLC as effector, together with the increase and mobilization of $\mathrm{Ca}^{2+}$ and release of the inhibitory neurotransmitter $\gamma$-aminobutyric acid (GABA) (Morera et al. 2016) (Fig. 4). of non-visual photoreceptors (bottom panel). This photocascade operates in ipRGCs and HCs expressing Opn4 proteins (Opn4m and Opn4x). Once a photon strikes Opn4 or another non-visual photopigment, 11-cis-retinal isomerizes to all-trans retinal (Retinal activation) activating a $\mathrm{Gq}$ protein that acts as a light signal transducer activating an effector protein, the enzyme phospholipase C (PLC) (signal amplification). In turn, PLC hydrolyzes the phosphoinositides ( $\mathrm{PIP}_{2}$ ), producing intracellular lipid mediators (inositol-triphosphates $\mathrm{IP}_{3}$ and diacylglycerol DAG) with the consequent $\mathrm{Ca}^{2+}$ mobilization inside the cell through inner reservoirs (IR) or transient potential channels located in the membrane (TRP) (Current Increase). The increase of $\mathrm{Ca}^{2+}$ inside the cell produces the depolarization of the membrane with the consequent release of the GABA neurotransmitter or other neurochemical signals in $\mathrm{HCs}$

In this connection, it has been recently reported that a subset of Opn4-expressing ipRGCs in mice releases GABA at nonimage-forming brain targets (Sonoda et al. 2020).

Although great advances have been achieved in terms of elucidating the mechanisms involved in non-canonical photopigment functions, many aspects remain unanswered yet.

Why do avian retinal horizontal cells express Opn4x? If we look at mammals, it is known that the organization of the mammalian neocortex is heavily implicated in the emergence of an advanced ability to integrate complex visual sensory information for the robust perception and recognition of visual objects, particularly faces. Birds do not have a neocortex, or at least they do not have a brain structure with six layers to match those of the mammalian neocortex (Clark et al. 2019). Jerison's principle of proper mass states that an increase in the size of a nervous system nucleus is associated with an increase in the processing power needed to meet behavioral requirements (Jerison 1973). An updated 
version of this principle could account not only for changes in size, but also for different patterns of protein expression requiring greater processing power. Is this the case for the avian retina? Can higher level processing of light stimulus in the retina compensate for what cannot be accomplished in the brain? The idea that sensory systems encode the salient features of the physical environment would support this hypothesis. In birds, higher processing requirements could be associated with flying and migration as well as visual acuity (Wylie et al. 2018). Strikingly, the INL containing the horizontal cells population is significantly larger in birds and other diurnal vertebrates in terms of size and cell number than in some mammals, mainly nocturnal rodents where most visual processing takes place in the visual cortex. Further behavioral and ethological studies could shed light on these issues. Overall, horizontal cells may have a key dual function in the retina of vertebrates, potentially regulating non-visual tasks together with their sister cells, ipRGCs, and in visual photoreceptors, modulating lateral interactions and retinal processing.

\section{Vertebrate Ancient Opsin (VA)}

The VA opsin was isolated and characterized from retinal cDNA of the Atlantic Salmon; it shows a 34-42\% aminoacid identity with the other opsin families and was included in the OPN1 family (comprising C-type opsins) (Soni and Foster 1997; Soni et al. 1998). VA was subsequently identified in other teleost fish such as zebrafish, common carp, smelt, roach, and agnatha (Yokoyama and Zhang 1997; Moutsaki et al. 2000; Minamoto and Shimizu 2002; Jenkins et al. 2003). VA was also found to be expressed in other species of non-mammalian vertebrates such as chicken and Xenopus being particularly concentrated in the retina, the pineal gland, and other brain areas. VA expression has been reconstituted in vitro with 11-cis-retinal and shown to be a functional photopigment with a $\lambda_{\max }$ between 470 and $500 \mathrm{~nm}$ (Soni et al. 1998; Kojima et al. 2000). In Rutilus retina, VA and Opn4 are expressed in horizontal cells, and a light stimulus at $470 \mathrm{~nm}$ promotes a depolarization response, suggesting a non-visual role of VA and Opn4 in this cell population (Jekins et al. 2003). In teleost and Xenopus, it is also present in a VA long isoform (VAL), a VA splicing variant, whose expression of this pigment by reconstitution with 11-cis-retinal in cell cultures after retinal light irradiation and isomerization, forms an intermediate with an absorption maximum in the visible spectrum able to activate $G_{i}$ and $G_{t}$ proteins (Sato et al. 2011). However, the active state of VA/ VAL does not convert back to the original photopigment, suggesting that VA/VAL display intermediate properties between vertebrate and invertebrate opsins (Sato et al. 2011). In birds, VA is expressed in the medio-basal hypothalamic area and co-localizes with gonadotropin-releasing hormone and arginine-vasotocin in neurosecretory neurons. The presence of VA in these two endocrine pathways strongly suggests a potential regulatory role of VA in the seasonal reproduction of birds (Álvarez-Viejo et al. 2003; GarcíaFernández et al. 2015).

\section{Encephalopsin (Opn3)}

Opn3 was originally designated as encephalopsin and then later became known as panopsin when it was found to be expressed within the retina and in extra-retinal tissues such as brain, testis, liver, and lung (Blackshaw and Snyder 1999; Halford et al. 2001, 2002; Tarttelin et al. 2003). Opn3 together with the TMT opsin belongs to the Opsin 3 family shown to be expressed in the brain, retina, and other tissues in humans, mice, birds, and teleosts. Phylogenetic analyses have suggested that the opsin 3 family is closely related to the vertebrate photoreceptor opsins and vertebrate ancient opsins (all of them comprised in C-type opsins group). Opn3 was the first opsin found in mice brain, particularly expressed in selective hypothalamic nuclei, in selected areas of cerebral cortex and Purkinje cells of the cerebellum (Blackshaw and Snyder 1999). Its orthologous TMT is expressed in some hypothalamic neurons and testis in chickens and teleosts. The presence of these opsins in multiple brain areas strongly suggests an extra-retinal photomodulation of the neurosecretory pathway in vertebrates (Moutsaki et al. 2003; Fischer et al. 2013; Kato et al. 2016). Moreover, several laboratories have been investigating the role of Opn3 in skin and tumor cells, suggesting that Opn3 may have extra-ocular functions in other tissues (Yoshimoto et al. 2018; Olinski et al. 2020; Xu et al. 2020). The presence of Opn3 in extra-ocular tissues has been related to the light-driven regulation of different functions (Koyanagi et al. 2013) such as wound-healing responses (CastellanoPellicena et al. 2019) and pigmentation of melanocytes (Regazzetti et al. 2018). Opn3 and TMT are blue-sensitive opsins that can activate $\mathrm{G}$ proteins in different ways with an absorption peak around $470 \mathrm{~nm}$. TMT activation involves $\mathrm{Gi}$, promoting a cAMP decrease, while the Opn3 activation of multiple species could involve a $\mathrm{G}$ protein other than $\mathrm{Gi}$ (Sugihara et al. 2016). Focusing on the vertebrate retina, Opn3 protein is expressed in the different neural layers including the GCL in the human retina (Halford et al. 2001). In chickens, it was recently shown that two Opn3-related proteins (cOpn3 and cTMT) are present in postnatal retinal horizontal cells, hypothalamus, and cerebellum (Kato et al. 2016). We have recently detected Opn 3 mRNA and protein in the whole chicken retina at early developmental stages from E7-10 up to postnatal days 10 (Rios et al. 2019). Opn3 expression was initially localized in cells of the forming 
GCL and extending throughout the inner developing retina; later, Opn3 immunoreactivity was also observed in INL and its plexiform layers (IPL and OPL) of retinal sections. Interestingly, Opn3 was also found to be expressed in Müller glial cells in chicken retina, and when these cells were kept in culture, levels of Opn3 protein were shown to be up-regulated by blue light exposure, this stimulation provoking long-lasting calcium responses (Rios et al. 2019). The precise role of Opn3 in the developing and mature retina of vertebrates needs to be further elucidated, though it is already apparent that levels of Opn3 protein and its intracellular localization are tightly regulated by blue stimulation in Müller glial cells (Rios et al. 2019), neurons (Rios et al., unpublished data), and melanocytes (Ozdeslik et al. 2019). Light stimulation was reported to have a significant effect on Opn3 levels and localization in primary Müller glial cells cultures through a mechanism of light induction dependent at least in part on de novo synthesis of protein (Rios et al. 2019).

\section{Neuropsin (Opn5)}

Opn5 was first described by Tartellin et al. (2003) and named neuropsin; its transcripts were found to be expressed in mouse testis, brain, and eye, as well as in human retina, brain, and spinal cord. In the rat, Opn5 mRNA and protein were reported to be expressed in the retina, specifically in INL and GCL cells and in IPL processes (Nieto et al. 2011). In human and mice retina, Opn5 is particularly seen in a subset of non-rod/non-cone retinal neurons and in the epidermal and muscle cells of the outer ears (Kojima et al. 2011). A non-visual opsin belonging to an independent group of the six families of opsins, the Opn5 gene was cloned in mice showing a 25-30\% identity with the rest of the opsins (Tarttelin et al. 2003). In chickens, this opsin is an UV-sensitive bistable pigment able to couple to Gi protein. Moreover, heterologous expression of the chicken Opn5 (cOpn5) in HEK-293 cells supplemented with 11-cis-retinal forms a UV-absorbing pigment and conversion to all-trans-retinal forms a visible-light absorbing molecule; this ability to interconvert the retinal indicates that cOpn5 is a bistable opsin (Yamashita et al. 2010). In HEK-293 cells expressing the human Opn5, UV-light stimulation affects the intracellular $\mathrm{Ca}^{2+}$ from internal stores and decreases intracellular cAMP levels (Sugiyama et al. 2014). Furthermore, the expression of Opn5 in the paraventricular organ in quails and chickens regulates the seasonal reproductive cycle through a neuroendocrine pathway controlling gonadal growth (Nakane et al. 2010; Kang and Kuenzel 2015). The presence of Opn5 and CRY1 in a small region of the caudal diencephalon in Xenopus laevis frog tadpoles plays an important role in the locomotor activity in response to UV light (Currie et al. 2016).
The most recent studies on the function of Opn5 in the retina show that it is expressed in a subpopulation of RGCs in the rat and mice retina (Nieto et al. 2011; Buhr et al. 2015; Benedetto et al. 2017). In the chicken, Opn5 was shown to be expressed in the pineal gland and in neurons of the INL and GCL of the retina of post-hatching chicks at PN14 (Yamashita et al. 2010), reflecting a similar retinal distribution in mammalian and non-mammalian retinas. Moreover, we have recently demonstrated that Opn5 mRNA and protein appeared very early in the developing retina at around E7-10, particularly in cells of the forming GCL and cells extending throughout the immature inner retina, resembling glial morphology (Rios et al. 2019). In addition, primary cultures of Müller glial cells clearly exhibited a positive immunoreactivity for Opn5-like protein (Rios et al. 2019).

In terms of potential roles, mice retina and cornea lacking Opn5 fail to photoentrain the molecular circadian clock to a regular LD cycle (Buhr and Gelder 2014, Bhur et al. 2015). Moreover, Opn5 has been recently associated with photoentrainment and phase-shifting to UV light (Ota et al. 2018); however, triple-knockout mice lacking essential components of phototransduction signaling for rods, cones, and ipRGCs, displayed minimal responses following UVlight stimulation, suggesting a very limited role for Opn5 in driving excitatory photic responses within the mouse retina (Hughes et al. 2016). Recently, a new role for Opn5 has been reported in the vascular development of mice retina. During mouse postnatal eye development, the vascular hyaloid network regresses from the vitreous as an adaptation for high-acuity vision, a process involving Opn5 and UV light from RGCs via a dopaminergic pathway. Opn5 loss of function led to a dopamine increase in the vitreous and resulted in premature hyaloid regression (Nguyen et al. 2019). The role of OPN5 is not limited to the retina, and it has also been expressed in mouse skin, melanocyte precursor cells, and hair and vibrissal follicles, where it has been shown to be necessary for the photoentrainment of the molecular clock of the skin (Buhr et al. 2019). Opn5 may assume differential roles in non-visual tasks across the different mammalian and non-mammalian vertebrate species, from seasonal reproductive control in birds to photoentrainment of the circadian clock in mammalian retina, cornea, and skin.

\section{Retinal G Protein-Coupled Receptor (RGR)}

As mentioned above, RGR is a photoisomerase expressed in the inner membranes of the RPE, within the retina (Hao and Fong 1996) in the end feet of Müller glial cells (Pandey et al. 1994) and in the GCL and ipRGCs in vertebrate inner retina (Díaz et al. 2017). RGR was shown to be present in chicken at the very early embryonic days of retina formation. In fact, around E8, RGR was located 
particularly in the GCL and in primary cultures of RGCs expressing Opn $4 \mathrm{x}$ and displaying net photosensitivity. At postnatal days, RGR remained expressed in the GCL, likely shifting in expression and localization to the Müller glial cells end feet (Díaz et al. 2017).

RGR was initially reported as a putative photoisomerase displaying two peaks of maximal absorption -at $370 \mathrm{~nm}$ and $469 \mathrm{~nm}$ - in the vicinity of the UV and blue regions, respectively (Hao and Fong 1996), sharing partial sequence homology with bovine rhodopsin (23\%) and squid retinochrome (26\%) (Shen et al. 1994). Furthermore, RGR binds all-trans-retinal as chromophore, which upon light stimulation can be partially photoisomerized into 11-cis-retinal. This body of evidence suggests that RGR could somehow act as a photoisomerase (Hao and Fong 1999) even though its low photosensitivity and the fact that its chromophore is not released after isomerization make it a weak candidate for this role. Retinas of RGR KO mice look morphologically normal, the only visible effect being the failure to regenerate rhodopsin as a consequence of retinyl ester accumulation, in turn causing RD with visual PRC loss (Chen et al. 2001). In addition, it was shown that RGR regulates the traffic of retinyl esters within RPE cells by means of the modulation of particular enzyme activities. In fact, RGR may act as a potential negative regulator of all-trans-retinyl ester hydrolase (REH) and lecithin:retinol:acyltransferase (LRAT) in the formation of retinyl esters in light (Radu et al. 2008). RGR interaction with cis- retinol dehydrogenase 5 (RDH5) to isomerize all-trans-retinal to 11-cis-retinal under light conditions (Maeda et al. 2003) may be a strong indication that there is an alternative route for the regeneration of 11-cis-retinoids in the visual cycle. Moreover, RGR may work as a functional photoisomerase in Müller glial cells (Morshedian et al. 2019). Co-expression of RGR and RDH10 produced a sustainable amount of 11-cis-retinol in light. Finally Morshedian et al. (2019) reported that retinas from RGR-/- lost sensitivity faster than retinas from $\mathrm{RGR}+/+$ mice; similar results were obtained with retinas treated with $\alpha$-aminoadipyc acid, a specific Müller glial cells toxin. It is noteworthy that RGR expression persists in the GCL at postnatal days. In addition to acting as a photoisomerase, further research infers that RGR also likely functions as a potential negative regulator of REH and LRAT in light (Radu et al. 2008). Pioneering work by (Díaz et al. 2017) using RGR knocked down in RGC cultures showed that levels of 11-cis-, all-trans-retinals, and all-trans-retinol were substantially higher than controls exposed just to light, whereas the content of all-trans-retinyl palmitate slightly decreased after RGR KD, with no significant differences in the light control. These findings support the idea that under physiological conditions and in light, RGR modulates the enzyme activities that maintain the balance in retinals and the retinyl ester pool, whereas when RGR expression is knocked down, the balance in the pool of retinoids is shifted to increase retinal and retinol content.

\section{The Visual Cycle in the Inner Retina and the Contribution of RGR}

A major difference between ciliary and rhabdomeric photopigments is the process of chromophore recycling. For ciliary opsins in the outer retina, the active form of the chromophore "11-cis-retinal" can be regenerated by two different mechanisms, the classical "visual cycle" involving the RPE and a second alternative visual cycle, mainly for cones, driven by Müller glial cells (Mata et al. 2002, reviewed in Díaz et al. 2016). Upon 11-cis- retinal photoisomerization into all-trans-retinal in the outer segments of PRCs, it is then reduced to alcohol by multiple membranebound retinol dehydrogenases (RDH5, RDH8 or RDH12) (Lhor and Salesse 2014). Once the all-trans-retinol is formed, it then diffuses into the RPE and is delivered to the intra-discal lumen, where it is esterified by LRAT to form all-trans-retinyl esters. As the cycle goes on, 11-cisretinal is newly regenerated and eventually rebound to the photopigment to form an active opsin (Batten et al. 2004; Kiser et al. 2014). A second visual cycle of retinal regeneration may take place between cones and Müller glial cells in a very similar manner to the classical RPE visual cycle. For this, the main substrate for the key enzyme in the cone visual cycle is a retinyl alcohol instead of a retinyl ester. In rhabdomeric opsins, on the other hand, upon light stimulation and after photoisomerization of 11-cis- to all-trans-retinal, retinal remains bound to the opsin, and a second photon at another specific wavelength is required to re-isomerizes it back to 11-cis-retinal. Rhabdomeric-type opsins usually exhibit a typical "bistable" nature forming thermally stable photoproducts with absorption maxima in the visible-light spectrum (Hillman 1979a, b; Terakita et al. 2008; Tsukamoto and Terakita 2010). In fact, they display an active form, or meta-state, which is a thermally stable form lasting seconds to minutes (Thapan et al. 2001; Güler et al. 2008). In this connection, mammalian Opn4 was proposed to behave as a bistable photopigment with only one silent state (Panda et al. 2005; Lin et al. 2008; Shirzad-Wasei et al. 2013); however, Opn4 photoequilibration was detected among stable states (Qiu et al. 2005; Do et al. 2009; Sexton et al. 2012), higly suggesting a "tristability" nature as demonstrated in a later report (Emanuel and Do 2015). Indeed, when light activates Opn4 in the ipRGCs, three states (two silent and one signaling state) were determined, indicating that such "tristability" may originate the signaling that drives physiological functions 
and behavior (reviewed in Do 2019). This stability condition may at least partially support ipRGC resistance to systemic vitamin A depletion (Thompson et al. 2004). Nevertheless, even though Opn4 may have these bi/tristability properties, it still needs to regenerate the retinaldehyde from neighboring stores. For this, some enzymes catalyzing the conversion of retinal to retinol and retinyl esters are required within the inner retina, since ipRGCs are placed far away from the PRC zone, the RPE and the OPL. In this regard, a secondary cycle of support for chromophore regeneration was shown to function in invertebrate eyes as described for Drosophila (Wang et al. 2010). An alternative chromophore recycling mechanism independent of light exposure may take place within the photoreceptor cell of invertebrates itself or in a closed second cell type that depends on isomerase and dehydrogenase enzymatic activities (Wang et al. 2010, 2012). In vertebrates, it could be hypothesized that this alternative mechamism occurs in the RGCs and/or in Müller glial cells of the retina. Müller glial cells were found to participate in the cone visual cycle on one side, and it is also known that they extend all through the inner retina, reaching the GCL and surrounding RGC somas with their end feet (reviewed in Díaz et al. 2016). However, it was initially believed that inner retinal photosensitivity was dependent on RPE support through visual cycle events (review in Sexton et al. 2012). Knockout animals for the key enzymes in the RPE visual cycle Rpe65 and Lrat showed a 100-fold lower sensitivity in PLRs compared with blind animals suffering RD (Lucas et al. 2001; Van Gelder et al. 2003). By contrast, ipRGC photosensitivity did not exhibit any change in isolated retinas of these knockout mice and treatment with all-transretinylamine (causing the acute poisoning of the RPE visual cycle) did not elicit any significant effect on PLRs in $\mathrm{rd} / \mathrm{rd}$ mice with only ipRGCs as functional photoreceptors (Tu et al. 2006). The exogenous administration of retinoids-mainly 11-cis- and 9-cis-retinal-in heterologous cellular expression systems promotes the highest photic responses, whereas the addition of all-trans-retinal elicits weaker responses than those obtained with cis-retinal; however, this lower response increases with (a) longer light exposure at high intensity levels and longer wavelengths (>540 nm), (b) full visible spectrum illumination exposure, (c) co-expression with arrestin (Melyan et al. 2005; Panda et al. 2005), and (d) 5 min of dark to recover full ipRGC activity in response to 1-min brief light pulses of $480 \mathrm{~nm}$ (Tu et al. 2005). Furthermore, recovery of activity in the dark requires a mechanism by which all-trans-retinal is converted back to 11-cis-retinal, as suggested in studies with purified recombinant Amphioxus Opn4 (Terakita et al. 2008). The above observations clearly demonstrate that (i) Opn4-dependent ipRGC photosensitivity is independent of the classical visual retinoid cycle, and (ii) there is a second, alternative cycle of chromophore regeneration. A secondary cycle is further supported by RGR expression and participation in the light regulation of the retinoid pool in isolated ipRGCs expressing Opn4x in chickens (Díaz et al. 2017). In addition, and as mentioned above, Müller glial cells exhibit closer contact with ipRGCs, possibly acting as the supporting second cell type for the alternative visual cycle in the inner retina, since the presence of novel visual cycle enzymes has been reported within the inner retina in the GCL (Kaylor et al. 2013, 2014). An alternative retinoid isomerization from all-trans-retinol to 11-cisretinol was shown to be catalyzed by a retinol isomerase named dihydroceramide desaturase- 1 (DES-1), identified as a putative Isomerase II (Kaylor et al. 2013) present in the GCL. The 11-cis-retinol thus formed can be stored as 11-cis-retinyl ester by action of the 11-cis ARAT. For this, two new 11-cis-specific retinyl ester synthases have been identified within the retina: the multifunctional O-acyltransferase (MFAT) (Kaylor et al. 2014) and diacylglycerol O-acyltransferase-1 (DGAT1) 8 (Kaylor et al. 2015), both found to be present in Müller glial cells and also in the GCL. In another series of studies, it was shown that primary embryonic cultures of Opn4x (+) RGCs were able to take up exogenous all-trans-retinal and isomerize it to 11-cis-retinal and other retinoids such as all-trans-retinol and all-trans-retinyl palmitate (Díaz et al. 2017). These observations clearly denote the presence and activity of a retinal dehydrogenase and a retinol acyl transferase in the RGC cultures from developing retina. In this connection, Opn4 (+) RGC cultures responded to light by increasing intracellular $\mathrm{Ca}^{2+}$ levels and showed significantly higher levels of 11-cis-retinal and all-trans-retinaldehyde levels than dark controls, clearly suggesting the bis/tristability of Opn4 (Díaz et al. 2017). Light exposure also substantially decreased all-trans-retinol content, whereas it increased levels of all-trans-retinyl palmitate, supporting the idea that light regulates the retinoid pool in the RGCs, increasing the retinyl esters store and content of 2 retinal isomers.

In addition to Opn4 intrinsic bi/tristability, and based on its localization, recovery after dark adaptation and presence of different retinoid enzymes/photoisomerases in the GCL (Kaylor et al. 2013; Díaz et al. 2017), a novel alternative visual cycle may occur in Opn4-expressing ipRGCs/horizontal cells and/or in the surrounding Müller glial cells to further contribute to the recycling of 11-cisretinal, providing the photopigment with the active form as well as with a pool of retinoids for later use as described in Drosophila (Wang et al. 2010, 2012). In this alternative process, RGR may contribute to modulation of the retinoid pools (retinals, retinols, and retinyl esters) in light, keeping the retinoid balance for future use upon light exposure (Díaz et al. 2017). 


\section{Retinal Neurons are not Alone in Expressing Photopigments and Responding to Light: Müller Glial Cells do as Well!}

Significant changes in somatic $\mathrm{Ca}^{2+}$ levels upon light stimulation, differentially provoking cell hyperpolarization or depolarization, are used to report intrinsic photic responses in diverse retinal cells such as visual PRCs, ipRGCs, and Opn4x-expressing horizontal cells (Qiu et al. 2005; Sekaran et al. 2005; Contín et al. 2010; Nieto et al. 2011; Meister and Tessier-Lavigne 2013; Morera et al. 2016; Díaz et al. 2017), denoting a typical characteristic of vertebrate photosensitivity. In line with this, it has recently been shown for the first time that chicken Müller glial cells in retina and primary cultures express Opn3 and Opn5-like proteins and respond to blue light (Fig. 4) (Rios et al. 2019). These cells expressing the typical markers for Müller glial cells (vimentin, glutamine synthase and glial fibrilar acidic protein) show increased levels of non-visual opsins upon 1-2 $\mathrm{h}$ light exposure and augmented intracellular $\mathrm{Ca}^{2+}$ after a brief blue light stimulation at $\sim 480 \mathrm{~nm}$ for at least $20 \mathrm{~s}$ (Fig. 4) (Rios et al. 2019). The human Müller glial cells line MIO-M1 was shown to express a number of different opsins and to respond to repetitive stimulation with $480 \mathrm{~nm}$ light (Hollborn et al. 2011). In terms of light responses, three different subpopulations of cells were observed in chicken Müller glial cells primary cultures with totally different levels of responsiveness-from high to no response- even though most cells express Opn3 and Opn5 photopigments. More than half the cultures responded to light with calcium increases, the remainder perhaps not having functional opsins in their membrane, requiring longer exposure times, higher blue light intensities, or activating a different signaling pathway independent of calcium mobilization, related to cyclic nucleotides, as previously described by Koyanagi et al (2013). Photic responses involving $\mathrm{Ca}^{+2}$ mobilization are nevertheless lost when cells are subjected to pretreatment with hydroxylamine (a retinaldehyde bleacher) in a similar manner to that previously found in intrinsically photosensitive horizontal cells (Morera et al. 2016). This evidence strongly indicates that such photosensitivity requires an active chromophore. On the other hand, experiments on indirect Müller glial cells responses to light showed that in $e x$-vivo conditions only a portion of Müller glial cells showed calcium increase in response to neuronal activation observed after light or electric stimulation (Newman 2005). In concordance with this, calcium increases in glial cells of isolated rat retina were evoked by light-induced neuronal activity, suggesting a neuron-to-glia signaling in the retina mediated by ATP release (Newman 2005). In a similar manner, in Müller glial cells of adult guinea pig retina, light stimulation evoked two differential $\mathrm{Ca}^{+2}$ responses (Rillich et al. 2009), probably causing glial activation by alterations in both the membrane potential and ATP-mediated mechanisms. Müller glial cells activation provoking calcium increase has been linked to ATP release (Newman 2003), extracellular $\mathrm{H}^{+}$flux (Tchernookova et al. 2018), and potentially D-serine release (Metea and Newman 2006). Strikingly, recent evidence indicates that Müller glial cells modify the 11-cis-retinol pool via RGRlight detection and, therefore, control cone photosenstivity (Morshedian et al. 2019). Likewise, Müller glial cells in vertebrates, via their instrinsic photosensitivity, may regulate pigment regeneration independently of the already known metabolic pathways (Morshedian et al. 2019). Nevertheless, further experiments will be required to fully understand the role of retinal glial cells under photic exposure conditions in the context of the entire retina and under pathophysiological conditions. Overall, Müller glial cells may play a pivotal role in non-visual processes regulated by light involving cell-to-cell or glia-to-neuron interactions. In this connection, glia participation in processes involving the synchronization of the circadian rhythms was recently reported, revealing that a cell-autonomous clock present in suprachiasmatic nucleus ( $\mathrm{SCN}$ ) astrocytes likely conducts circadian behavior in mammals (Brancaccio et al. 2019) and acts as living optic fibers or enhancers of human visual acuity in the optical and visual functions, respectively (MacDonald et al. 2017).

\section{Non-visual Opsins and Continuous Light Exposure}

Light itself is a vital source of earthly energy and life, responsible for the regulation of a number of image-forming and NIF activities. Light detection by specialized retinal visual and non-visual photoreceptors triggers vision-associated functions involving image formation, a significant number of reflex and subconscious activities, light regulation of melatonin and its regulatory enzyme AA-NAT in the retina, synchronization of retinal clocks, and glia-to-neuron interaction, among others (Fig. 3) (Valdez et al. 2009, 2012, 2013, 2015; Guido et al. 2010). Most of these functions are controlled by different brain areas that receive direct projections from the retina via the RGC axons (Berson et al. 2002; Guido et al. 2010). The prolonged and persistent changes in environmental lighting conditions ushered in by modern life styles, with continuous artificial lighting day and night, night exposure to daylight tablets, notebooks, cell phones, LED screens, televisions, etc., night work shifts, or transmeridian flights, all cause marked alterations in human physiology and behavior, such alterations include sleep disturbances, the desynchronization of daily behavioral, and hormonal 
rhythms. Even though the retina is the neural portion of the eye responsible for capturing photons and transmitting all this information to other structures in the brain; excessive light exposure may be harmful to the tissues and may cause retinal damage (Contín et al. 2016). People are currently more exposed to light than they were 10 years ago, especially through excessive exposure during nighttime. Both domestic and public light sources and devices (cell phones, tablets, computers, etc.) expose the retina to light for hours on end, even at night. Such extended periods of exposure pose a rapidly growing risk in modern society with a potential harmfulness in retinal physiology. Potential damage to the visual system by artificial light exposure should, therefore, be considered part of the environmental factors influencing physiological processes such as desynchronization of circadian rhythms in metabolism and behavioral patterns, with all that this entails. It has been demonstrated that different light sources of the same or even lower intensity (lux) do not necessarily pose the same degree of retinal risk. For millennia, life on Earth has been exposed to sunlight with alternating day/night, and the visual system from invertebrates to vertebrates has evolved under these laws of nature. With the arrival of artificial light, we first became exposed to incandescent light, considered to be reliable artificial light owing to its similarity to the sunlight spectrum. However, human population growth produced the need to reduce the use of energy, promoting the gradual replacement of incandescent lighting with low-energy lamps like compact fluorescent lamps (CFL) at first, and then LED sources. Excess exposure to blue light has had an even more detrimental effect, leading to increased abnormal intolerance to visual perception of light, a common symptom in disorders such as dry eye, blepharitis, retinal dystrophy, blepharospasm, traumatic brain injury, depression, and anxiety, among others (Marek et al. 2019).

An important body of evidence suggests that retinal damage depends upon the wavelength, intensity, and period of light, as well as the type of animal model used (Noell et al. 1966; Noell 1979; Penn et al. 1985; Organisciak et al. 1998; Grimm et al. 2001; Wenzel et al. 2005; Ahamed Basha et al. 2014). All the cited reports agree on the degenerative effect of light (Contín et al. 2016) and that these processes are photopigment-triggered events. The effect of LED on retinas from Wistar rats in the context of LD cycles of illumination shows an early retinal injury after 7 days of exposure, suggesting that LED devices may be more injurious than fluorescent light. The exposure of adult Wistar rats to constant white LED sources from 1 to 8-day periods at 200 lux (LL1-LL8) shows classical PRC death after 7 days of continuous light exposure, a slow degenerative process. However, besides the classical photoreceptor cells are deep affected by constant light as reported (Contin et al. 2013; Benedetto and Contin 2019), the inner retina is not significantly affected by LED sources at 200 lux of intensity. However, there are clear changes in the localization and protein expression of opsins Opn4 and Opn5, indicating a compensatory mechanism of protection against excess low light in non-visual photoreceptors, specifically in ipRGCs and INL cells expressing Opn4 or Opn5 (Benedetto et al. 2017). Thus, constant light promotes retinal remodeling with classical photoreceptor death and a re-location of photopigments responsible for sensing light in the inner retina.

\section{Regulation of Photopigment Expression in a Cyclic Light Environment}

Retinal photo-detectors have the ability to adapt to enormous changes in the intensity and spectral composition of light, which fluctuate daily in line with the Earth's rotation, going from as little as $0.001 \mathrm{~lx}$ of intensity on a moonless night to more than 100,000 lx during a bright day. In other words, these photosystems perform their functions with light levels that can vary over a 100 million fold range during the day (Cronin et al. 2014). While modulating visual sensitivity, the retina also needs to deal with the deleterious effects of high-intensity light and spectral composition mainly in the blue and UV-light regions, as mentioned above. In fact, the physiology of the retina is regulated rhythmically both by direct response to light and by the control exerted by biological clocks (reviewed in Felder-Schmittbuhl et al. 2018; Guido et al. 2010; Ko 2020; McMahon et al. 2014).

Throughout evolution, living beings have developed biochemical mechanisms capable of measuring time and regulating physiology and behavior according to the phase of the day. These mechanisms are named biological clocks and the functions they control, circadian rhythms (Bass and Lazar 2016); they allow organisms to better adapt to daily and repetitive changes in the environment (Ouyang et al. 1998). The circadian clock, at the molecular level, consists of a group of genes called "clock genes" that regulate one another through interconnected negative feedback mechanisms involving their own transcription and translation (Takahashi 2017). Circadian clocks can control between 5 and $20 \%$ of the genes that are expressed in the whole organism, depending on the type of cell or tissue involved, and approximately $50 \%$ oscillate in any one of them (Mure et al. 2018; Takahashi 2017; Zhang et al. 2014); in retina, hundreds of transcripts oscillate daily (Bailey et al. 2004; Mure et al. 2018; Storch et al. 2007). Biological clocks are present in virtually all tissues and organs. At the systemic level, they are coordinated and entrained with the environment by the hypothalamic SCN, the main pacemaker in mammals coupled to the LD cycle by the retina via the retino-hypothalamic track (Guido et al. 1999; Hastings et al. 2019; Rusak 
and Boulos 1981), particularly Opn4 (+) ipRGCs (reviewed in Diaz et al. 2016; Guido et al. 2010).

Circadian clocks were first identified in vertebrate retina by studying the rhythms of melatonin metabolism (Besharse and Iuvone 1983; Tosini and Menaker 1996). Many aspects of retinal physiology are modulated by light and circadian clocks, for example: (i) visual sensitivity, which is manifested in the oscillations observed in electroretinograms (Barnard et al. 2006; Cameron et al. 2008; Manglapus et al. 1998; McGoogan and Cassone 1999; Storch et al. 2007); (ii) ipRGC-driven PLRs to blue light exposure peaking at midday (Valdez et al. IOVS 2015), (iii) phagocytosis of shed photoreceptor OS (Bobu and Hicks 2009; LaVail 1980); (iv) dopamine and melatonin levels (Doyle et al. 2002a, 2002b; Garbarino-Pico et al. 2004b; Hamm and Menaker 1980; Tosini and Menaker 1996; Wirz-Justice et al. 1984); (v) susceptibility to light damage (Organisciak et al. 2000), (vi) phospholipid metabolism in different retinal cell types in animals subject to constant darkness (DD) or LL (Garbarino-Pico et al. 2004a, 2005; Guido et al. 2001); (vii) cGMP-gated cationic channels (Ko et al. 2001, 2003); (viii) photoreceptor gap-junction coupling (Ribelayga et al. 2008); and $i x$ ) gene expression (Bailey et al. 2004; Green and Besharse 1996; Mure et al. 2018; Pierce et al. 1993; Storch et al. 2007). We will now focus on the temporal regulation of retinal photopigment expression as part of the retina's adaptation to daily variations in ambient light.

In the early 1990s, McGinnis et al. described a relationship between photic (non-circadian) changes in the expression of visual cell gene products, their location, and phototransduction in murine PRCs (McGinnis et al. 1992). Later, the first circadian rhythm in gene expression described in the retina was precisely that for the expression of an opsin, when Pierce et al. reported the rhythm of the iodopsin messenger in chicken embryonic photoreceptor cultures (Pierce et al. 1993). The transcript of this red-sensitive cone pigment presents a peak late in the day before cone-disc shedding, suggesting a tight coordination between the degradation of the protein along with the OS of the cone shedding, and its de novo biosynthesis. In Arvicanthis ansorgei, a diurnal rodent, the levels of rhodopsin, a short- and mid-wavelength sensitive cone opsin, and Opn4 mRNAs presented rhythms of expression both under a LD cycle and in DD (denoting a true circadian rhythm), although their amplitude decreased in constant conditions (Bobu et al. 2013). In this species, rhythms are also observed in the phagocytosis of photoreceptor outer segment (Bobu and Hicks 2009). In mice, high-amplitude circadian rhythms are also observed in UV opsin and rhodopsin mRNAs (von Schantz et al. 1999), and in zebrafish, a tight correlation between LWS opsin mRNA expression and cone sensitivity was reported ( $\mathrm{Li}$ et al. 2005).

In relation to non-visual opsins, it was reported in rat inner retina that Opn4 mRNA levels oscillate under both LD and DD cycles, indicating that they are regulated by biological clocks (Hannibal et al. 2005; Sakamoto et al. 2004). This is in contrast to another study reporting the disappearance of this rhythm in DD (Mathes et al. 2007). Nevertheless, these authors agree that the Opn4 mRNA presents a peak near the LD transition (Hannibal et al. 2005; Mathes et al. 2007; Sakamoto et al. 2004). Interestingly, under long photoperiods, levels remain elevated for a longer time than under short photoperiods, i.e., the expression is seasonally regulated (Mathes et al. 2007). Using an RD model in which PRCs are lost, Sakamoto et al. showed that the rhythm of Opn4 expression is lost in the absence of cones and rods (Sakamoto et al. 2004). Importantly, in rats, Opn4-containing ipRGCs adjust their sensitivity in response to light (Weng et al. 2009; Wong et al. 2005). In the diurnal rodent Arvicanthis ansorgei, the Opn4 messenger also shows a daily rhythm in LD, although with a peak in the transition from $\mathrm{D}$ to $\mathrm{L}$, in contrast to what is observed in rats. This oscillation is lost in DD, which would suggest that it is not a circadian-controlled oscillation; however, in LL, it shows a high-amplitude rhythm but with a peak almost in antiphase with that observed in LD (Bobu et al. 2013). By comparing the expression of melanopsin in this diurnal rodent with that observed in other nocturnal animals, the authors propose that it could be linked to adaptation to different photic niches (Bobu et al. 2013). In chickens, circadian rhythms in Opn4 mRNA levels have also been described in both the retina and pineal; Opn4 messenger is expressed in all retinal cell layers and other parts of the brain with a nocturnal peak in PRCs and a diurnal peak in INL and RPE (Chaurasia et al. 2005). In zebrafish, two of the $O p n 4-$ related genes expressed in the retina make it a robust diurnal rhythm (Matos-Cruz et al. 2011). RGR and the retinal pigment epithelium derived from the rhodopsin homolog (peropsin, $R r h$ ) are also subject to circadian regulation in the chicken retina and pineal gland, being highest at late subjective day (Bailey and Cassone 2004). Taken together, these studies strongly support the hypothesis that both photic and circadian regulations of photopigment expression contribute to the precise adaptation of the retina to daily changes in ambient light conditions.

\section{Concluding Remarks}

There is growing evidence that the inner retina of vertebrates contains a number of photosensitive cells, neurons (ipRGCs and horizontal cells), and glia (Müller glial cells) bearing different photoactive molecules, the non-visual photopigments Opn3, Opn4, Opn5, and the photoisomerase RGR. Most of these photopigments share the characteristic of responding to light near the blue region within the visible spectrum (with higher energy), probably related to the efficacy and penetrance of light in reaching deep brain 
structures as well as the fish in the depth of the water, revealing a potential evolutionary significance and also reflecting the spectral composition of light at twilight. In addition, these opsins appear very early in development, even before any perceptible sign of visual responses. This strongly denotes the early capacity of these cells to sense light and environmental illumination conditions across time (day and night), necessary for the formation of the organism. Strikingly, this photosensitivity remains active even under different RD situations of visual PRCs (cones and rods) that lead to blindness. On the contrary, photosensitive cells of the inner retina appear to be resistant to light damage, exhibiting responses involving relocalization of Opn4 and Opn5 photopigments. These photoreceptors are mainly involved in NIF-subconscious and -reflex activities and may supplement the visual function associated with imaging. Moreover, these cells are intrinsically sensitive to blue light of long duration, showing sustained responses ( $\mathrm{sec}$ to $\mathrm{min}$ ) by triggering photocascades that involve, in most cases, a vitamin A derivative as chromophore, a Gq protein, calcium mobilization, and membrane depolarization, with GABA release under certain circumstances. In fact, inner retinal cells expressing Opn3, Opn4, and Opn5 display intrinsic photosensitivity whereas the presence of RGR and diverse key enzymes involved in an alternative visual cycle provide cells with the ability to recycle the chromophore/retinoids in light or dark even when they are far from the outer retina and the RPE.

These photosensitive cells are in charge of setting the local clock within the retina but are also involved in the synchronization of circadian rhythms in the whole organism, PLRs, the acute suppression of pineal melatonin, mood, sleep, and even of some visual functions, via a number of retinal projections to diverse brain areas. They conform a cellular network likely acting in processes of lateral interaction through horizontal cells in contact with cones and rods, and/or cooperating with ipRGCs in NIF functions and through Müller glial cells. They also potentially collaborate in events related to retinoid recycling and/or to neuron-glia or glia-glia interactions under prolonged light stimuli. Further studies are required to elucidate the ability of the inner retina to resist light damage and to determine the molecular mechanisms triggered after light stimulation under pathophysiological conditions. The contribution of non-visual opsins in the processing of light in vertebrates, including humans, also requires further exploration.

Acknowledgements This work has been supported by Agencia Nacional de Promoción Científica y Técnica (FONCyT, PICT 2016 No 0187 and 2017 No 631), Consejo Nacional de Investigaciones Científicas y Tecnológicas de la República Argentina (CONICET) (PIP 2014), and Secretaría de Ciencia y Tecnología de la Universidad Nacional de Córdoba (SeCyT-UNC, Consolidar 2018-2022). Authors are grateful to Ciencia Hoy for authorizing the partial use of Figure 1 from Guido ME (2016) Ciencia Hoy 151, 43-46. ISSN 1666-5171.
Author Contributions All authors (MEG, NAM, MNR, NMD, LPM, EGP and MAC) contributed to the first draft of the manuscript, performed the literature search and data analysis, and critically revised the work. The illustrations were made by MEG, NMD and MNR. The last version was written by MEG and all authors commented on previous versions of the manuscript, read and approved the final version.

\section{Compliance with Ethical Standards}

Conflict of interest The authors declare that the research was conducted in the absence of any commercial or financial relationships that could be construed as a potential conflict of interest.

\section{References}

Ahamed Basha A, Mathangi DC, Shyamala R, Ramesh Rao K (2014) Protective effect of light emitting diode phototherapy on fluorescent light induced retinal damage in Wistar strain albino rats. Ann Anat. https://doi.org/10.1016/j.aanat.2014.04.004

Álvarez-Viejo M, Cernuda-Cernuda R, DeGrip WJ et al (2003) Colocalization of mesotocin and opsin immunoreactivity in the hypothalamic preoptic nucleus of Xenopus laevis. Brain Res. https://doi.org/10.1016/S0006-8993(03)02273-X

Araki M, Kimura H (1991) GABA-like immunoreactivity in the developing chick retina: differentiation of GABAergic horizontal cell and its possible contacts with photoreceptors. J Neurocytol. https ://doi.org/10.1007/BF01355531

Badea TC, Cahill H, Ecker J et al (2009) Distinct roles of transcription factors Brn3a and Brn3b in controlling the development, morphology, and function of retinal ganglion cells. Neuron. https:// doi.org/10.1016/j.neuron.2009.01.020

Bailey MJ, Beremand PD, Hammer R, Reidel E, Thomas TL, Cassone VM (2004) Transcriptional profiling of circadian patterns of mRNA expression in the chick retina. J Biol Chem 279:5224752254. https://doi.org/10.1074/jbc.M405679200

Bailey MJ, Cassone VM (2004) Opsin photoisomerases in the chick retina and pineal gland: characterization, localization, and circadian regulation. Investig Ophthalmol Vis Sci 45:769-775. https ://doi.org/10.1167/iovs.03-1125

Bailey MJ, Cassone VM (2005) Melanopsin expression in the chick retina and pineal gland. Mol Brain Res. https://doi.org/10.1016/j. molbrainres.2004.11.003

Barnard AR, Hattar S, Hankins MW, Lucas RJ (2006) Melanopsin regulates visual processing in the mouse retina. Curr Biol. https ://doi.org/10.1016/j.cub.2005.12.045

Bass J, Lazar MA (2016) Circadian time signatures of fitness and disease. Science 354:994-999. https://doi.org/10.1126/scien ce.aah4965

Batten ML, Imanishi Y, Maeda T et al (2004) Lecithin-retinol acyltransferase is essential for accumulation of all-trans-retinyl esters in the eye and in the liver. J Biol Chem. https://doi.org/10.1074/ jbc.M312410200

Beaudry FEG, Iwanicki TW, Mariluz BRZ et al (2017) The non-visual opsins: eighteen in the ancestor of vertebrates, astonishing increase in ray-finned fish, and loss in amniotes. J Exp Zool Part B Mol Dev Evol. https://doi.org/10.1002/jez.b.22773

Bellingham J, Chaurasia SS, Melyan Z et al (2006) Evolution of melanopsin photoreceptors: discovery and characterization of a new melanopsin in nonmammalian vertebrates. PLoS Biol. https:// doi.org/10.1371/journal.pbio.0040254

Bellingham J, Wells DJ, Foster RG (2003) In silico characterisation and chromosomal localisation of human RRH (peropsin) 
- Implications for opsin evolution. BMC Genomics. https://doi. org/10.1186/1471-2164-4-3

Benedetto MM, Contin MA (2019) Oxidative stress in retinal degeneration promoted by constant LED light. Front Cell Neurosci. https ://doi.org/10.3389/fncel.2019.00139

Benedetto MM, Guido ME, Contin MA (2017) Non-visual photopigments effects of constant light-emitting diode light exposure on the inner retina of Wistar rats. Front Neurol. https://doi. org/10.3389/fneur.2017.00417

Berson DM, Castrucci AM, Provencio I (2010) Morphology and mosaics of melanopsin-expressing retinal ganglion cell types in mice. J Comp Neurol. https://doi.org/10.1002/cne.22381

Berson DM, Dunn FA, Takao M (2002) Phototransduction by retinal ganglion cells that set the circadian clock. Science. https://doi. org/10.1126/science. 1067262

Besharse JC, Iuvone PM (1983) Circadian clock in Xenopus eye controlling retinal serotonin $\mathrm{N}$-acetyltransferase. Nature 305:133135. https://doi.org/10.1038/305133a0

Blackshaw S, Snyder SH (1999) Encephalopsin: a novel mammalian extraretinal opsin discretely localized in the brain. J Neurosci. https://doi.org/10.1523/jneurosci.19-10-03681.1999

Bono J, Clopath C (2019) Synaptic plasticity onto inhibitory neurons as a mechanism for ocular dominance plasticity. PLoS Comput Biol. https://doi.org/10.1371/journal.pcbi.1006834

Bowmaker JK, Heath LA, Wilkie SE, Hunt DM (1997) Visual pigments and oil droplets from six classes of photoreceptor in the retinas of birds. Vision Res. https://doi.org/10.1016/S0042 -6989(97)00026-6

Brancaccio M, Edwards MD, Patton AP et al (2019) Cell-autonomous clock of astrocytes drives circadian behavior in mammals. Science 363:187. https://doi.org/10.1126/science.aat4104

Brown TM, Gias C, Hatori M et al (2010) Melanopsin contributions to irradiance coding in the thalamo-cortical visual system. PLoS Biol. https://doi.org/10.1371/journal.pbio.1000558

Buhr ED, Van Gelder RN (2014) Local photic entrainment of the retinal circadian oscillator in the absence of rods, cones, and melanopsin. Proc Natl Acad Sci USA. https://doi.org/10.1073/ pnas. 1323350111

Buhr ED, Vemaraju S, Diaz N et al (2019) Neuropsin (OPN5) mediates local light-dependent induction of circadian clock genes and circadian photoentrainment in exposed murine skin. Curr Biol. https://doi.org/10.1016/j.cub.2019.08.063

Buhr ED, Yue WWS, Ren X et al (2015) Neuropsin (OPN5)-mediated photoentrainment of local circadian oscillators in mammalian retina and cornea. Proc Natl Acad Sci USA. https://doi.org/10.1073/ pnas. 1516259112

Bobu C, Hicks D (2009) Regulation of retinal photoreceptor phagocytosis in a diurnal mammal by circadian clocks and ambient lighting. Investig Ophthalmol Vis Sci 50:3495-3502. https://doi. org/10.1167/iovs.08-3145

Bobu C, Sandu C, Laurent V, Felder-Schmittbuhl MP, Hicks D (2013) Prolonged light exposure induces widespread phase shifting in the circadian clock and visual pigment gene expression of the Arvicanthis ansorgei retina. Mol Vis 19:1060-1073

Cameron MA, Barnard AR, Lucas RJ (2008) The electroretinogram as a method for studying circadian rhythms in the mammalian retina. J Genet 87:459-466. https://doi.org/10.1007/s1204 1-008-0068-5

Castellano-Pellicena I, Uzunbajakava NE, Mignon C et al (2019) Does blue light restore human epidermal barrier function via activation of Opsin during cutaneous wound healing? Lasers Surg Med. https://doi.org/10.1002/lsm.23015

Chaurasia SS, Rollag MD, Jiang G et al (2005) Molecular cloning, localization and circadian expression of chicken melanopsin (Opn4): differential regulation of expression in pineal and retinal cell types. J Neurochem. https://doi.org/10.11 11/j.1471-4159.2004.02874.x

Chen P, Hao W, Rife L et al (2001) A photic visual cycle of rhodopsin regeneration is dependent on Rgr. Nat Genet. https://doi. org/10.1038/90089

Cheng N, Tsunenari T, Yau KW (2009) Intrinsic light response of retinal horizontal cells of teleosts. Nature. https://doi.org/10.1038/ nature 08175

Clark WJ, Porter B, Colombo M (2019) Searching for face-category representation in the avian visual forebrain. Front Physiol. https ://doi.org/10.3389/fphys.2019.00140

Contín MA, Arietti MM, Benedetto MM et al (2013) Photoreceptor damage induced by low-intensity light: model of retinal degeneration in mammals. Mol Vis 19:1614-1625

Contín MA, Benedetto MM, Quinteros-Quintana ML, Guido ME (2016) Light pollution: the possible consequences of excessive illumination on retina. Eye 30(2):255-263. https://doi. org/10.1038/eye.2015.221

Contín M, Verra DM, Guido ME et al (2006) An invertebrate-like phototransduction cascade mediates light detection in the chicken retinal ganglion cells. FASEB J. https://doi.org/10.1096/fj.066133fje

Contín MA, Verra DM, Salvador G et al (2010) Light activation of the phosphoinositide cycle in intrinsically photosensitive chicken retinal ganglion cells. Investig Ophthalmol Vis Sci. https://doi. org/10.1167/iovs.10-5643

Cronin TW, Johnsen S, Marshall NJ, Warrant EJ (2014) Visual ecology. Princeton University Press, Princeton

Currie SP, Doherty GH, Sillar KT (2016) Deep-brain photoreception links luminance detection to motor output in Xenopus frog tadpoles. Proc Natl Acad Sci USA. https://doi.org/10.1073/ pnas. 1515516113

Dacey DM, Liao HW, Peterson BB et al (2005) Melanopsin-expressing ganglion cells in primate retina signal colour and irradiance and project to the LGN. Nature. https://doi.org/10.1038/nature03387

Davies WL, Hankins MW, Foster RG (2010) Vertebrate ancient opsin and melanopsin: divergent irradiance detectors. Photochem Photobiol Sci. https://doi.org/10.1039/c0pp00203h

Darwin C (1859) On the origin of species by means of natural selection, or, the preservation of favoured races in the struggle for life. J. Murray, London

Devlin PF, Kay SA (2001) Circadian photoperception. Annu Rev Physiol. https://doi.org/10.1146/annurev.physiol.63.1.677

Diamond JS (2017) Inhibitory interneurons in the retina: types, circuitry, and function. Annu Rev Vis Sci. https://doi.org/10.1146/ annurev-vision-102016-061345

Díaz NM, Morera LP, Guido ME (2016) Melanopsin and the nonvisual photochemistry in the inner retina of vertebrates. Photochem Photobiol 92(1):29-44. https://doi.org/10.1111/php.12545

Díaz NM, Morera LP, Tempesti T, Guido ME (2017) The visual cycle in the inner retina of chicken and the involvement of retinal G-protein-coupled receptor (RGR). Mol Neurobiol. https://doi. org/10.1007/s12035-016-9830-5

Díaz NM, Morera LP, Verra DM et al (2014) Early appearance of nonvisual and circadian markers in the developing inner retinal cells of chicken. Biomed Res Int. https://doi.org/10.1155/2014/646847

Do MTH (2019) Melanopsin and the intrinsically photosensitive retinal ganglion cells: biophysics to behavior. Neuron 104(2):205-226. https://doi.org/10.1016/j.neuron.2019.07.016

Do MTH, Kang SH, Xue T et al (2009) Photon capture and signalling by melanopsin retinal ganglion cells. Nature. https://doi. org/10.1038/nature07682

Doyle SE, Grace MS, McIvor W, Menaker M (2002) Circadian rhythms of dopamine in mouse retina: the role of melatonin. Vis Neurosci 19:593-601. https://doi.org/10.1017/s0952523802195058 
Doyle SE, McIvor WE, Menaker M (2002) Circadian rhythmicity in dopamine content of mammalian retina: role of the photoreceptors. J Neurochem 83:211-219. https://doi.org/10.104 6/j.1471-4159.2002.01149.x

Ebihara S, Tsuji K (1980) Entrainment of the circadian activity rhythm to the light cycle: effective light intensity for a Zeitgeber in the retinal degenerate $\mathrm{C} 3 \mathrm{H}$ mouse and the normal C57BL mouse. Physiol Behav. https://doi.org/10.1016/00319384(80)90246-2

Ecker JL, Dumitrescu ON, Wong KY et al (2010) Melanopsin-expressing retinal ganglion-cell photoreceptors: cellular diversity and role in pattern vision. Neuron. https://doi.org/10.1016/j.neuro n.2010.05.023

Emanuel AJ, Do MTH (2015) Melanopsin tristability for sustained and broadband phototransduction. Neuron. https://doi.org/10.1016/j. neuron.2015.02.011

Felder-Schmittbuhl MP et al (2018) Ocular clocks: adapting mechanisms for eye functions and health. Investig Ophthalmol Vis Sci 59:4856-4870. https://doi.org/10.1167/iovs.18-24957

Fernandez DC, Fogerson PM, Lazzerini Ospri L et al (2018) Light affects mood and learning through distinct retina-brain pathways. Cell. https://doi.org/10.1016/j.cell.2018.08.004

Fischer RM, Fontinha BM, Kirchmaier S et al (2013) Co-expression of VAL- and TMT-opsins uncovers ancient photosensory interneurons and motorneurons in the vertebrate brain. PLoS Biol. https ://doi.org/10.1371/journal.pbio.1001585

Foster RG, Hankins MW (2002) Non-rod, non-cone photoreception in the vertebrates. Prog Retin Eye Res. https://doi.org/10.1016/ s1350-9462(02)00036-8

Foster RG, Provencio I, Hudson D et al (1991) Circadian photoreception in the retinally degenerate mouse (rd/rd). J Comp Physiol A. https://doi.org/10.1007/BF00198171

Freedman MS, Lucas RJ, Soni B et al (1999) Regulation of mammalian circadian behavior by non-rod, non-cone, ocular photoreceptors. Science. https://doi.org/10.1126/science.284.5413.502

Garbarino-Pico E, Carpentieri AR, Castagnet PI, Pasquare SJ, Giusto NM, Caputto BL, Guido ME (2004) Synthesis of retinal ganglion cell phospholipids is under control of an endogenous circadian clock: daily variations in phospholipid-synthesizing enzyme activities. J Neurosci Res 76:642-652. https://doi.org/10.1002/ jnr.20126

Garbarino-Pico E et al (2004) Retinal ganglion cells are autonomous circadian oscillators synthesizing $\mathrm{N}$-acetylserotonin during the day. J Biol Chem 279:51172-51181. https://doi.org/10.1074/jbc. M309248200

Garbarino-Pico E et al (2005) Rhythms of glycerophospholipid synthesis in retinal inner nuclear layer cells. Neurochem Int 47:260 270. https://doi.org/10.1016/j.neuint.2005.04.024

García-Fernández JM, Cernuda-Cernuda R, Davies WIL et al (2015) The hypothalamic photoreceptors regulating seasonal reproduction in birds: a prime role for VA opsin. Front Neuroendocrinol. https://doi.org/10.1016/j.yfrne.2014.11.001

Gehring WJ, Ikeo K (1999) Pax 6: mastering eye morphogenesis and eye evolution. Trends Genet 15(9):371-377. https://doi. org/10.1016/s0168-9525(99)01776-x

Gerkema MP, Davies WIL, Foster RG et al (2013) The nocturnal bottleneck and the evolution of activity patterns in mammals. Proc R Soc B Biol Sci 280(1765):20130508. https://doi.org/10.1098/ rspb.2013.0508

Green CB, Besharse JC (1996) Identification of a novel vertebrate circadian clock-regulated gene encoding the protein nocturnin. Proc Natl Acad Sci USA 93:14884-14888. https://doi.org/10.1073/ pnas.93.25.14884

Grimm C, Wenzel A, Williams TP et al (2001) Rhodopsin-mediated blue-light damage to the rat retina: effect of photoreversal of bleaching. Investig Ophthalmol Vis Sci 42(2):497-505
Guido ME, Garbarino Pico E, Caputto BL (2001) Circadian regulation of phospholipid metabolism in retinal photoreceptors and ganglion cells. J Neurochem 76:835-845. https://doi.org/10.104 6/j.1471-4159.2001.00081.x

Guido ME, Garbarino-Pico E, Contin MA et al (2010) Inner retinal circadian clocks and non-visual photoreceptors: novel players in the circadian system. Prog Neurobiol 92(4):484-504. https://doi. org/10.1016/j.pneurobio.2010.08.005

Guido ME, Goguen D, De Guido L, Robertson HA, Rusak B (1999) Circadian and photic regulation of immediate-early gene expression in the hamster suprachiasmatic nucleus. Neuroscience 90:555-571. https://doi.org/10.1016/s0306-4522(98)00467-9

Güler AD, Ecker JL, Lall GS et al (2008) Melanopsin cells are the principal conduits for rod-cone input to non-image-forming vision. Nature. https://doi.org/10.1038/nature06829

Halford S, Bellingham J, Ocaka L et al (2002) Assignment1 of panop$\sin (\mathrm{OPN} 3)$ to human chromosome band 1q43 by in situ hybridization and somatic cell hybrids. Cytogenet Cell Genet. https:// doi.org/10.1159/000059351

Halford S, Freedman MS, Bellingham J et al (2001) Characterization of a novel human opsin gene with wide tissue expression and identification of embedded and flanking genes on chromosome 1q43. Genomics. https://doi.org/10.1006/geno.2001.6469

Hamm HE, Menaker M (1980) Retinal rhythms in chicks: circadian variation in melantonin and serotonin $\mathrm{N}$-acetyltransferase activity. Proc Natl Acad Sci USA 77:4998-5002. https://doi. org/10.1073/pnas.77.8.4998

Hankins MW, Peirson SN, Foster RG (2008) Melanopsin: an exciting photopigment. Trends Neurosci 31:27-36. https://doi. org/10.1016/j.tins.2007.11.002

Hannibal J, Georg B, Hindersson P, Fahrenkrug J (2005) Light and darkness regulate melanopsin in the retinal ganglion cells of the albino Wistar rat. J Mol Neurosci 27:147-155. https://doi. org/10.1385/JMN:27:2:147

Hannibal J, Hindersson P, Østergaard J et al (2004) Melanopsin is expressed in PACAP-containing retinal ganglion cells of the human retinohypothalamic tract. Investig Ophthalmol Vis Sci. https://doi.org/10.1167/iovs.04-0313

Hao W, Fong HKW (1996) Blue and ultraviolet light-absorbing opsin from the retinal pigment epithelium. Biochemistry. https://doi. org/10.1021/bi952420k

Hao W, Fong HKW (1999) The endogenous chromophore of retinal G protein-coupled receptor opsin from the pigment epithelium. J Biol Chem. https://doi.org/10.1074/jbc.274.10.6085

Hastings MH, Maywood ES, Brancaccio M (2019) The mammalian circadian timing system and the suprachiasmatic nucleus as its pacemaker. Biology 8:13. https://doi.org/10.3390/biology801 0013

Hattar S, Liao HW, Takao M et al (2002) Melanopsin-containing retinal ganglion cells: architecture, projections, and intrinsic photosensitivity. Science. https://doi.org/10.1126/science.1069609

Hattar S, Lucas RJ, Mrosovsky N et al (2003) Melanopsin and rodcone photoreceptive systems account for all major accessory visual functions in mice. Nature. https://doi.org/10.1038/natur e01761

Hillman P (1979a) Bistable and sensitizing pigments in vision. Biophys Struct Mech. https://doi.org/10.1007/BF00535440

Hillman P (1979b) Introduction to the Symposium on bistable and sensitizing pigments in vision. Biophys Struct Mech. https://doi. org/10.1007/BF00535441

Hollborn M, Ulbricht E, Rillich K, Dukic-Stefanovic S, Wurm A, Wagner L, Reichenbach A, Wiedemann P, Limb GA, Bringmann A, Kohen L (2011) The human Müller cell line MIO-M1 expresses opsins. Mol Vis 17:2738-2750

Hughes S, Rodgers J, Hickey D et al (2016) Characterisation of light responses in the retina of mice lacking principle components of 
rod, cone and melanopsin phototransduction signalling pathways. Sci Rep. https://doi.org/10.1038/srep28086

Hunt DM, Dulai KS, Partridge JC et al (2001) The molecular basis for spectral tuning of rod visual pigments in deep-sea fish. J Exp Biol 204:11606607

Jenkins A, Muñoz M, Tarttelin EE et al (2003) VA opsin, melanopsin, and an inherent light response within retinal interneurons. Curr Biol. https://doi.org/10.1016/S0960-9822(03)00509-8

Jerison HJ (1973) Evolution of the brain and intelligence. Academy Press, New York

Jiang Z, Yue WWS, Chen L et al (2018) Cyclic-nucleotide- and HCNchannel-mediated phototransduction in intrinsically photosensitive retinal ganglion cells. Cell 175(3):652-664.e12. https://doi. org/10.1016/j.cell.2018.08.055

Kang SW, Kuenzel WJ (2015) Deep-brain photoreceptors (DBPs) involved in the photoperiodic gonadal response in an avian species, Gallus gallus. Gen Comp Endocrinol. 211:106. https://doi. org/10.1016/j.ygcen.2014.11.020

Kato M, Sugiyama T, Sakai K et al (2016) Two opsin 3-related proteins in the chicken retina and brain: a TMT-type opsin 3 is a blue-light sensor in retinal horizontal cells, hypothalamus, and cerebellum. PLoS ONE. https://doi.org/10.1371/journal.pone.0163925

Kaylor JJ, Cook JD, Makshanoff J et al (2014) Identification of the 11-cis-specific retinyl-ester synthase in retinal Müller cells as multifunctional O-Acyltransferase (MFAT). Proc Natl Acad Sci USA. https://doi.org/10.1073/pnas.1319142111

Kaylor JJ, Radu RA, Bischoff N et al (2015) Diacylglycerol O-acyltransferase type- 1 synthesizes retinyl esters in the retina and retinal pigment epithelium. PLoS ONE. https://doi.org/10.1371/ journal.pone. 0125921

Kaylor JJ, Yuan Q, Cook J et al (2013) Identification of DES1 as a vitamin A isomerase in Müller glial cells of the retina. Nat Chem Biol. https://doi.org/10.1038/nchembio.1114

Keeler CE (1927) Iris movement in blind mice. Am J Physiol Content. https://doi.org/10.1152/ajplegacy.1927.81.1.107

Kiser PD, Golczak M, Palczewski K (2014) Chemistry of the retinoid (visual) cycle. Chem Rev. https://doi.org/10.1021/cr400107q

Ko GY (2020) Circadian regulation in the retina: from molecules to network. Eur J Neurosci 51:194-216. https://doi.org/10.1111/ ejn. 14185

Ko GY, Ko ML, Dryer SE (2001) Circadian regulation of cGMP-gated cationic channels of chick retinal cones. Erk MAP Kinase and $\mathrm{Ca}$ 2+/calmodulin-dependent protein kinase II. Neuron 29:255266. https://doi.org/10.1016/s0896-6273(01)00195-7

Ko GY, Ko ML, Dryer SE (2003) Circadian phase-dependent modulation of cGMP-gated channels of cone photoreceptors by dopamine and D2 agonist. J Neurosci 23:3145-3153. https://doi. org/10.1523/JNEUROSCI.23-08-03145.2003

Kojima D, Mano H, Fukada Y (2000) Vertebrate ancient-Long opsin: a green-sensitive photoreceptive molecule present in zebrafish deep brain and retinal horizontal cells. J Neurosci. https://doi. org/10.1523/jneurosci.20-08-02845.2000

Kojima D, Mori S, Torii M et al (2011) UV-sensitive photoreceptor protein OPN5 in humans and mice. PLoS ONE. https://doi. org/10.1371/journal.pone.0026388

Koyanagi M, Kubokawa K, Tsukamoto H et al (2005) Cephalochordate melanopsin: evolutionary linkage between invertebrate visual cells and vertebrate photosensitive retinal ganglion cells. Curr Biol. https://doi.org/10.1016/j.cub.2005.04.063

Koyanagi M, Takada E, Nagata T et al (2013) Homologs of vertebrate Opn3 potentially serve as a light sensor in nonphotoreceptive tissue. Proc Natl Acad Sci USA. https://doi.org/10.1073/pnas.12194 16110

Koyanagi M, Terakita A (2014) Diversity of animal opsin-based pigments and their optogenetic potential. Biochim Biophys Acta. https://doi.org/10.1016/j.bbabio.2013.09.003
Koyanagi M, Terakita A (2008) Gq-coupled rhodopsin subfamily composed of invertebrate visual pigment and melanopsin. Photochem Photobiol. https://doi.org/10.1111/j.1751-1097.2008.00369.x

Lamb TD (2013) (2013) Evolution of phototransduction, vertebrate photoreceptors and retina. Prog Retin Eye Res 36:52-119. https ://doi.org/10.1016/j.preteyeres.2013.06.001

Lamb TD, Collin SP, Pugh EN (2007) Evolution of the vertebrate eye: opsins, photoreceptors, retina and eye cup. Nat Rev Neurosci 8(12):960-976. https://doi.org/10.1038/nrn2283

LaVail MM (1980) Circadian nature of rod outer segment disc shedding in the rat. Investig Ophthalmol Vis Sci 19:407-411

Lhor M, Salesse C (2014) Retinol dehydrogenases: membrane-bound enzymes for the visual function1. Biochem Cell Biol. https://doi. org/10.1139/bcb-2014-0082

Li P, Temple S, Gao Y, Haimberger TJ, Hawryshyn CW, Li L (2005) Circadian rhythms of behavioral cone sensitivity and long wavelength opsin mRNA expression: a correlation study in zebrafish. J Exp Biol 208:497-504. https://doi.org/10.1242/jeb.01424

Lin B, Koizumi A, Tanaka N et al (2008) Restoration of visual function in retinal degeneration mice by ectopic expression of melanopsin. Proc Natl Acad Sci USA. https://doi.org/10.1073/pnas.08061 14105

Lucas RJ (2013) Mammalian inner retinal photoreception. Curr Biol. https://doi.org/10.1016/j.cub.2012.12.029

Lucas RJ, Douglas RH, Foster RG (2001) Characterization of an ocular photopigment capable of driving pupillary constriction in mice. Nat Neurosci. https://doi.org/10.1038/88443

Lucas RJ, Freedman MS, Muñoz M et al (1999) Regulation of the mammalian pineal by non-rod, non-cone, ocular photoreceptors. Science. https://doi.org/10.1126/science.284.5413.505

Lucas RJ, Hattar S, Takao M et al (2003) Diminished pupillary light reflex at high irradiances in melanopsin-knockout mice. Science. https://doi.org/10.1126/science.1077293

MacDonald RB, Charlton-Perkins M, Harris WA (2017) Mechanisms of Müller glial cell morphogenesis. Curr Opin Neurobiol. https ://doi.org/10.1016/j.conb.2017.08.005

Maeda T, Van Hooser JP, Driessen CAGG et al (2003) Evaluation of the role of the retinal G protein-coupled receptor (RGR) in the vertebrate retina in vivo. J Neurochem. https://doi.org/10.104 6/j.1471-4159.2003.01741.x

Manglapus MK, Uchiyama H, Buelow NF, Barlow RB (1998) Circadian rhythms of rod-cone dominance in the Japanese quail retina. J Neurosci 18:4775-4784

Marek V, Reboussin E, Dégardin-Chicaud J et al (2019) Implication of melanopsin and trigeminal neural pathways in blue light photosensitivity in vivo. Front Neurosci. https://doi.org/10.3389/fnins .2019 .00497

Mata NL, Radu RA, Clemmons RS, Travis GH (2002) Isomerization and oxidation of vitamin A in cone-dominant retinas: a novel pathway for visual-pigment regeneration in daylight. Neuron. https://doi.org/10.1016/S0896-6273(02)00912-1

Mathes A, Engel L, Holthues H, Wolloscheck T, Spessert R (2007) Daily profile in melanopsin transcripts depends on seasonal lighting conditions in the rat retina. J Neuroendocrinol 19:952-957. https://doi.org/10.1111/j.1365-2826.2007.01608.x

Matos-Cruz V, Blasic J, Nickle B, Robinson PR, Hattar S, Halpern ME (2011) Unexpected diversity and photoperiod dependence of the zebrafish melanopsin system. PLoS ONE 6:e25111. https://doi. org/10.1371/journal.pone.0025111

McGinnis JF, Whelan JP, Donoso LA (1992) Transient, cyclic changes in mouse visual cell gene products during the light-dark cycle. J Neurosci Res 31:584-590. https://doi.org/10.1002/jnr.490310325

McGoogan JM, Cassone VM (1999) Circadian regulation of chick electroretinogram: effects of pinealectomy and exogenous melatonin. Am J Physiol 277:R1418-1427. https://doi.org/10.1152/ajpre gu.1999.277.5.R1418 
McMahon DG, Iuvone PM, Tosini G (2014) Circadian organization of the mammalian retina: from gene regulation to physiology and diseases. Prog Retin Eye Res 39:58-76. https://doi. org/10.1016/j.preteyeres.2013.12.001

Meister M, Tessier-Lavigne M (2013) Low-level visual processing: the retina. Princ Neural Sci Fifth Ed

Melyan Z, Tarttelin EE, Bellingham J et al (2005) Addition of human melanopsin renders mammalian cells photoresponsive. Nature. https://doi.org/10.1038/nature03344

Metea MR, Newman EA (2006) Calcium signaling in specialized glial cells. Glia. https://doi.org/10.1002/glia.20352

Minamoto T, Shimizu I (2002) A novel isoform of vertebrate ancient opsin in a smelt fish, Plecoglossus altivelis. Biochem Biophys Res Commun. https://doi.org/10.1006/bbrc.2001.6186

Moore RY (1995) Neural control of the pineal gland. Behav Brain Res. https://doi.org/10.1016/0166-4328(96)00083-6

Morera LP, Díaz NM, Guido ME (2016) Horizontal cells expressing melanopsin $\mathrm{x}$ are novel photoreceptors in the avian inner retina. Proc Natl Acad Sci USA. https://doi.org/10.1073/pnas.16089 01113

Morshedian A, Kaylor JJ, Ng SY et al (2019) Light-driven regeneration of cone visualpPigments through a mechanism involving RGR opsin in müller glial cells. Neuron. https://doi. org/10.1016/j.neuron.2019.04.004

Moutsaki P, Bellingham J, Soni BG et al (2000) Sequence, genomic structure and tissue expression of carp (Cyprinus carpio L.) vertebrate ancient (VA) opsin. FEBS Lett. https://doi. org/10.1016/S0014-5793(00)01550-7

Moutsaki P, Whitmore D, Bellingham J et al (2003) Teleost multiple tissue (tmt) opsin: a candidate photopigment regulating the peripheral clocks of zebrafish? Mol Brain Res. https://doi. org/10.1016/S0169-328X(03)00059-7

Mure LS et al (2018) Diurnal transcriptome atlas of a primate across major neural and peripheral tissues. Science. https:// doi.org/10.1126/science.aao0318

Nakane Y, Ikegami K, Ono H et al (2010) A mammalian neural tissue opsin (Opsin 5) is a deep brain photoreceptor in birds. Proc Natl Acad Sci USA. https://doi.org/10.1073/pnas.1006393107

Nelson DE, Takahashi JS (1991) Sensitivity and integration in a visual pathway for circadian entrainment in the hamster (Mesocricetus auratus). J Physiol. https://doi.org/10.1113/jphys iol.1991.sp018660

Newman EA (2005) Calcium increases in retinal glial cells evoked by light-induced neuronal activity. J Neurosci. https://doi. org/10.1523/JNEUROSCI.1354-05.2005

Newman EA (2003) Glial cell inhibition of neurons by release of ATP. J Neurosci. https://doi.org/10.1523/jneurosci.23-0501659.2003

Nguyen MTT, Vemaraju S, Nayak G et al (2019) An opsin 5-dopamine pathway mediates light-dependent vascular development in the eye. Nat Cell Biol. https://doi.org/10.1038/s41556-019-0301-x

Nieto PS, Valdez DJ, Acosta-Rodríguez VA, Guido ME (2011) Expression of novel opsins and intrinsic light responses in the mammalian retinal ganglion cell line RGC-5. Presence of Opn5 in the rat retina. PLoS ONE. https://doi.org/10.1371/journal.pone.0026417

Noell WK (1979) Effects of environmental lighting and dietary vitamin a on the vulnerability of the retina to light damage. Photochem Photobiol. https://doi.org/10.1111/j.1751-1097.1979.tb07756.x

Noell WK, Walker VS, Kang BS, Berman S (1966) Retinal damage by light in rats. Invest Ophthalmol 5(5):450-473

Olinski LE, Lin EM, Oancea E (2020) Illuminating insights into opsin 3 function in the skin. Adv Biol Regul. https://doi.org/10.1016/j. jbior.2019.100668

Organisciak DT, Darrow RM, Barsalou L et al (1998) Light history and age-related changes in retinal light damage. Investig Ophthalmol Vis Sci 39(7):1107-1116
Organisciak DT, Darrow RM, Barsalou L, Kutty RK, Wiggert B (2000) Circadian-dependent retinal light damage in rats. Investig ophthalmol Vis Sci 41:3694-3701

Ota W, Nakane Y, Hattar S, Yoshimura T (2018) Impaired circadian photoentrainment in Opn5-null mice. iScience. https://doi. org/10.1016/j.isci.2018.08.010

Ouyang Y, Andersson CR, Kondo T, Golden SS, Johnson CH (1998) Resonating circadian clocks enhance fitness in cyanobacteria. Proc Natl Acad Sci USA 95:8660-8664. https://doi.org/10.1073/ pnas.95.15.8660

Ozdeslik RN, Olinski LE, Trieu MM et al (2019) Human nonvisual opsin 3 regulates pigmentation of epidermal melanocytes through functional interaction with melanocortin 1 receptor. Proc Natl Acad Sci USA. https://doi.org/10.1073/pnas.1902825116

Panda S, Nayak SK, Campo B et al (2005) Illumination of the melanopsin signaling pathway. Science. https://doi.org/10.1126/scien ce. 1105121

Panda S, Provencio I, Tu DC et al (2003) Melanopsin is required for non-image-forming photic responses in blind mice. Science. https://doi.org/10.1126/science.1086179

Pandey S, Blanks JC, Spee C et al (1994) Cytoplasmic retinal localization of an evolutionary homolog of the visual pigments. Exp Eye Res. https://doi.org/10.1006/exer.1994.1055

Peirson SN, Haiford S, Foster RG (2009) The evolution of irradiance detection: melanopsin and the non-visual opsins. Philos Trans R Soc B Biol Sci. https://doi.org/10.1098/rstb.2009.0050

Penn JS, Baker BN, Howard AG, Williams TP (1985) Retinal lightdamage in albino rats: lysosomal enzymes, rhodopsin, and age. Exp Eye Res. https://doi.org/10.1016/S0014-4835(85)80017-8

Pierce ME, Sheshberadaran H, Zhang Z, Fox LE, Applebury ML, Takahashi JS (1993) Circadian regulation of iodopsin gene expression in embryonic photoreceptors in retinal cell culture. Neuron 10:579-584. https://doi.org/10.1016/0896-6273(93)90161-j

Poché RA, Reese BE (2009) Retinal horizontal cells: challenging paradigms of neural development and cancer biology. Development. https://doi.org/10.1242/dev.033175

Porter ML, Blasic JR, Bok MJ et al (2011) Shedding new light on opsin evolution. Proc R Soc B Biol Sci. https://doi.org/10.1098/ rspb.2011.1819

Provencio I, Foster RG (1993) Vitamin A2-based photopigments within the pineal gland of a fully terrestrial vertebrate. Neurosci Lett. https://doi.org/10.1016/0304-3940(93)90713-U

Provencio I, Jiang G, De Grip WJ et al (1998) Melanopsin: an opsin in melanophores, brain, and eye. Proc Natl Acad Sci USA. https:// doi.org/10.1073/pnas.95.1.340

Provencio I, Loew ER, Foster RG (1992) Vitamin A2-based visual pigments in fully terrestrial vertebrates. Vis Res. https://doi. org/10.1016/0042-6989(92)90084-V

Provencio I, Rodriguez IR, Jiang G et al (2000) A novel human opsin in the inner retina. J Neurosci. https://doi.org/10.1523/JNEUR OSCI.20-02-00600.2000

Provencio I, Rollag MD, Castrucci AM (2002) Photoreceptive net in the mammalian retina. This mesh of cells may explain how some blind mice can still tell day from night. Nature. https://doi. org/10.1038/415493a

Qiu X, Kumbalasiri T, Carlson SM et al (2005) Induction of photosensitivity by heterologous expression of melanopsin. Nature. https ://doi.org/10.1038/nature03345

Radu RA, Hu J, Peng J et al (2008) Retinal pigment epithelium-retinal $\mathrm{G}$ protein receptor-opsin mediates light-dependent translocation of all-trans-retinyl esters for synthesis of visual chromophore in retinal pigment epithelial cells. J Biol Chem. https://doi. org/10.1074/jbc.M801288200

Raible F, Tessmar-Raible K, Arboleda E et al (2006) Opsins and clusters of sensory G-protein-coupled receptors in the sea urchin genome. Dev Biol. https://doi.org/10.1016/j.ydbio.2006.08.070 
Regazzetti C, Sormani L, Debayle D et al (2018) Melanocytes sense blue light and regulate pigmentation through opsin-3. J Invest Dermatol. https://doi.org/10.1016/j.jid.2017.07.833

Ribelayga C, Cao Y, Mangel SC (2008) The circadian clock in the retina controls rod-cone coupling. Neuron 59:790-801. https:// doi.org/10.1016/j.neuron.2008.07.017

Rillich K, Gentsch J, Reichenbach A et al (2009) Light stimulation evokes two different calcium responses in Müller glial cells of the guinea pig retina. Eur J Neurosci. https://doi.org/10.111 1/j.1460-9568.2009.06682.x

Rios MN, Marchese NA, Guido ME (2019) Expression of non-visual opsins Opn3 and Opn5 in the developing inner retinal cells of birds. Light-responses in müller glial cells. Front Cell Neurosci. https://doi.org/10.3389/fncel.2019.00376

Roenneberg T, Foster RG (1997) Twilight times: light and the circadian system. Photochem Photobiol. https://doi. org/10.1111/j.1751-1097.1997.tb03188.x

Rusak B, Boulos Z (1981) Pathways for photic entrainment of mammalian circadian rhythms. Photochem Photobiol 34:267-273. https ://doi.org/10.1111/j.1751-1097.1981.tb08996.x

Sakai K, Yamashita T, Imamoto Y, Shichida Y (2015) Diversity of active states in TMT opsins. PLoS ONE. https://doi.org/10.1371/ journal.pone.0141238

Sakamoto K, Liu C, Tosini G (2004) Classical photoreceptors regulate melanopsin mRNA levels in the rat retina. J Neurosci 24:96939697. https://doi.org/10.1523/JNEUROSCI.2556-04.2004

Santillo S, Orlando P, De Petrocellis L et al (2006) Evolving visual pigments: hints from the opsin-based proteins in a phylogenetically old "eyeless" invertebrate. BioSystems. https://doi.org/10.1016/j. biosystems.2006.03.008

Sato K, Yamashita T, Ohuchi H, Shichida Y (2011) Vertebrate ancientlong opsin has molecular properties intermediate between those of vertebrate and invertebrate visual pigments. Biochemistry. https://doi.org/10.1021/bi201212z

Schmidt TM, Chen SK, Hattar S (2011) Intrinsically photosensitive retinal ganglion cells: many subtypes, diverse functions. Trends Neurosci. https://doi.org/10.1016/j.tins.2011.07.001

Schmidt TM, Kofuji P (2009) Functional and morphological differences among intrinsically photosensitive retinal ganglion cells. J Neurosci. https://doi.org/10.1523/JNEUROSCI.4117-08.2009

Sekaran S, Lupi D, Jones SL et al (2005) Melanopsin-dependent photoreception provides earliest light detection in the mammalian retina. Curr Biol. https://doi.org/10.1016/j.cub.2005.05.053

Sexton TJ, Golczak M, Palczewski K, Van Gelder RN (2012) Melanopsin is highly resistant to light and chemical bleaching in vivo. J Biol Chem. https://doi.org/10.1074/jbc.M111.325969

Shen D, Jiang M, Hao W et al (1994) A human opsin-related gene that encodes a retinaldehyde-binding protein. Biochemistry. https:// doi.org/10.1021/bi00248a022

Shichida Y, Matsuyama T (2009) Evolution of opsins and phototransduction. Philos Trans R Soc B Biol Sci. https://doi.org/10.1098/ rstb.2009.0051

Shirzad-Wasei N, Van Oostrum J, Bovee-Geurts PH et al (2013) Large scale expression and purification of mouse melanopsin- $\mathrm{L}$ in the baculovirus expression system. Protein Express Purif. https://doi. org/10.1016/j.pep.2013.07.010

Sondereker KB, Stabio ME, Renna JM (2020) Crosstalk: the diversity of melanopsin ganglion cell types has begun to challenge the canonical divide between image-forming and non-image-forming vision. J Comp Neurol. https://doi.org/10.1002/cne.24873

Soni BG, Foster RG (1997) A novel and ancient vertebrate opsin. FEBS Lett. https://doi.org/10.1016/S0014-5793(97)00287-1

Soni BG, Philp AR, Foster RG, Knox BE (1998) Novel retinal photoreceptors [3]. Nature. https://doi.org/10.1038/27794

Sonoda T, Lee SK, Birnbaumer L, Schmidt TM (2018) Melanopsin phototransduction is repurposed by ipRGC subtypes to shape the function of distinct visual circuits. Neuron. https://doi. org/10.1016/j.neuron.2018.06.032

Sonoda T, Li JY, Hayes NW et al (2020) A noncanonical inhibitory circuit dampens behavioral sensitivity to light. Science. https ://doi.org/10.1126/science.aay3152

Storch KF, Paz C, Signorovitch J, Raviola E, Pawlyk B, Li T, Weitz CJ (2007) Intrinsic circadian clock of the mammalian retina: importance for retinal processing of visual information. Cell 130:730-741. https://doi.org/10.1016/j.cell.2007.06.045

Sugihara T, Nagata T, Mason B et al (2016) Absorption characteristics of vertebrate non-visual opsin, Opn3. PLoS ONE. https:// doi.org/10.1371/journal.pone.0161215

Sugiyama T, Suzuki H, Takahashi T (2014) Light-induced rapid $\mathrm{Ca} 2+$ response and MAPK phosphorylation in the cells heterologously expressing human OPN5. Sci Rep. https://doi. org/10.1038/srep05352

Sun L, Kawano-Yamashita E, Nagata T et al (2014) Distribution of mammalian-like melanopsin in cyclostome retinas exhibiting a different extent of visual functions. PLoS ONE. https://doi. org/10.1371/journal.pone.0108209

Takahashi JS (2017) Transcriptional architecture of the mammalian circadian clock. Nat Rev Genet 18:164-179. https://doi. org/10.1038/nrg.2016.150

Tarttelin EE, Bellingham J, Hankins MW et al (2003) Neuropsin (Opn5): a novel opsin identified in mammalian neural tissue. FEBS Lett. https://doi.org/10.1016/S0014-5793(03)01212-2

Tchernookova BK, Heer C, Young M et al (2018) Activation of retinal glial (Müller) cells by extracellular ATP induces pronounced increases in extracellular H+ flux. PLoS ONE. https ://doi.org/10.1371/journal.pone.0190893

Terakita A (2005) The opsins. Genome Biol. https://doi.org/10.1186/ gb-2005-6-3-213

Terakita A, Nagata T (2014) Functional properties of opsins and their contribution to light-sensing physiology. Zool Sci. https://doi. org/10.2108/zs140094

Terakita A, Tsukamoto H, Koyanagi M et al (2008) Expression and comparative characterization of Gq-coupled invertebrate visual pigments and melanopsin. J Neurochem. https://doi.org/10.11 11/j.1471-4159.2007.05184.x

Tessier-Lavigne M (1991) Phototransduction and information processing in the retina. In: Kandel ER, Schwartz JH, Jessell TM (eds) Principles of neural science, 3rd edn. Appleton \& Lange, Norwalk, pp 401-418

Thapan K, Arendt J, Skene DJ (2001) An action spectrum for melatonin suppression: evidence for a novel non-rod, noncone photoreceptor system in humans. J Physiol. https://doi. org/10.1111/j.1469-7793.2001.t01-1-00261.x

Thompson CL, Selby CP, Van Gelder RN et al (2004) Effect of vitamin A depletion on nonvisual phototransduction pathways in cryptochromeless mice. J Biol Rhythms. https://doi. org/10.1177/0748730404270519

Tomonari S, Takagi A, Noji S, Ohuchi H (2007) Expression pattern of the melanopsin-like (cOpn4m) and VA opsin-like genes in the developing chicken retina and neural tissues. Gene Expr Patterns. https://doi.org/10.1016/j.modgep.2007.06.001

Tosini G, Menaker M (1996) Circadian rhythms in cultured mammalian retina. Science 272:419-421. https://doi.org/10.1126/ science.272.5260.419

Tsukamoto H, Terakita A (2010) Diversity and functional properties of bistable pigments. Photochem Photobiol Sci. https://doi. org/10.1039/c0pp00168f

Tu DC, Owens LA, Anderson L et al (2006) Inner retinal photoreception independent of the visual retinoid cycle. Proc Natl Acad Sci USA 103:10426-10431. https://doi.org/10.1073/ pnas.0600917103 
Tu DC, Zhang D, Demas J et al (2005) Physiologic diversity and development of intrinsically photosensitive retinal ganglion cells. Neuron. https://doi.org/10.1016/j.neuron.2005.09.031

Valdez DJ, Garbarino-Pico E, Díaz NM et al (2012) Differential regulation of arylalkylamine $\mathrm{N}$-acetyltransferase activity in chicken retinal ganglion cells by light and circadian clock. Chronobiol Int. https://doi.org/10.3109/07420528.2012.707160

Valdez DJ, Nieto PS, Della Costa NS et al (2015) Circadian control of the pupillary light responses in an avian model of blindness, the GUCY1* chickens. Investig Ophthalmol Vis Sci. https://doi. org/10.1167/iovs.14-15481

Valdez DJ, Nieto PS, Díaz NM et al (2013) Differential regulation of feeding rhythms through a multiple-photoreceptor system in an avian model of blindness. FASEB J. https://doi.org/10.1096/ fj.12-222885

Valdez DJ, Nieto PS, Garbarino-Pico E et al (2009) A nonmammalian vertebrate model of blindness reveals functional photoreceptors in the inner retina. FASEB J. https://doi.org/10.1096/fj.08-11708 5

Van Gelder RN, Wee R, Lee JA, Tu DC (2003) Physiology: reduced pupillary light responses in mice lacking cryptochromes. Science. https://doi.org/10.1126/science.1079536

Verra DM, Contín MA, Hicks D, Guido ME (2011) Early onset and differential temporospatial expression of melanopsin isoforms in the developing chicken retina. Investig Ophthalmol Vis Sci. https ://doi.org/10.1167/iovs.11-75301

Von Schantz M, Lucas RJ, Foster RG (1999) Circadian oscillation of photopigment transcript levels in the mouse retina. Brain Res Mol Brain Res 72:108-114. https://doi.org/10.1016/s0169 $-328 x(99) 00209-0$

Wang X, Wang T, Jiao Y et al (2010) Requirement for an enzymatic visual cycle in Drosophila. Curr Biol. https://doi.org/10.1016/j. cub.2009.12.022

Wang X, Wang T, Ni JD et al (2012) The drosophila visual cycle and de novo chromophore synthesis depends on rdhB. J Neurosci. https ://doi.org/10.1523/JNEUROSCI.5350-11.2012

Wee R, Van Gelder RN (2004) Sleep disturbances in young subjects with visual dysfunction. Ophthalmology. https://doi. org/10.1016/j.ophtha.2003.05.014

Weng S, Wong KY, Berson DM (2009) Circadian modulation of melanopsin-driven light response in rat ganglion-cell photoreceptors. J Biol Rhythm 24:391-402. https://doi.org/10.1177/07487 30409343767

Wenzel A, Grimm C, Samardzija M, Remé CE (2005) Molecular mechanisms of light-induced photoreceptor apoptosis and neuroprotection for retinal degeneration. Prog Retin Eye Res. https ://doi.org/10.1016/j.preteyeres.2004.08.002

Wirz-Justice A, Da Prada M, Reme C (1984) Circadian rhythm in rat retinal dopamine. Neurosci Lett 45:21-25. https://doi. org/10.1016/0304-3940(84)90323-9
Wong KY, Dunn FA, Berson DM (2005) Photoreceptor adaptation in intrinsically photosensitive retinal ganglion cells. Neuron 48:1001-1010. https://doi.org/10.1016/j.neuron.2005.11.016

Wylie DR, Gutiérrez-Ibáñez C, Gaede AH et al (2018) Visual-cerebellar pathways and their roles in the control of avian flight. Front Neurosci. https://doi.org/10.3389/fnins.2018.00223

Xu C, Wang R, Yang Y et al (2020) Expression of OPN3 in lung adenocarcinoma promotes epithelial-mesenchymal transition and tumor metastasis. Thorac Cancer. https://doi. org/10.1111/1759-7714.13254

Yamashita T, Ohuchi H, Tomonari S et al (2010) Opn5 is a UV-sensitive bistable pigment that couples with Gi subtype of $\mathrm{G}$ protein. Proc Natl Acad Sci USA. https://doi.org/10.1073/pnas.10124 98107

Yamashita T, Ono K, Ohuchi H et al (2014) Evolution of mammalian Opn5 as a specialized UV-absorbing pigment by a single amino acid mutation. J Biol Chem. https://doi.org/10.1074/jbc. M113.514075

Yarfitz S, Hurley JB (1994) Transduction mechanisms of vertebrate and invertebrate photoreceptors. J Biol Chem 269:14329-14332

Yau KW, Hardie RC (2009) Phototransduction motifs and variations. Cell. https://doi.org/10.1016/j.cell.2009.09.029

Yokoyama S, Zhang H (1997) Cloning and characterization of the pineal gland-specific opsin gene of marine lamprey (Petromyzon marinus). Gene. https://doi.org/10.1016/S0378-1119(97)00458-7

Yoshimoto T, Morine Y, Takasu C et al (2018) Blue light-emitting diodes induce autophagy in colon cancer cells by Opsin 3. Ann Gastroenterol Surg. https://doi.org/10.1002/ags3.12055

Yoshimura T, Ebihara S (1996) Spectral sensitivity of photoreceptors mediating phase-shifts of circadian rhythms in retinally degenerate CBA/J $(\mathrm{rd} / \mathrm{rd})$ and normal CBA/N $(+/+)$ mice. J Comp Physiol A. https://doi.org/10.1007/BF00225828

Zeitzer JM, Dijk DJ, Kronauer RE et al (2000) Sensitivity of the human circadian pacemaker to nocturnal light: melatonin phase resetting and suppression. J Physiol. https://doi.org/10.111 $1 / j .1469-7793.2000 .00695 . x$

Zhang R, Lahens NF, Ballance HI, Hughes ME, Hogenesch JB (2014) A circadian gene expression atlas in mammals: implications for biology and medicine. Proc Natl Acad Sci USA 111:1621916224. https://doi.org/10.1073/pnas.1408886111

Publisher's Note Springer Nature remains neutral with regard to jurisdictional claims in published maps and institutional affiliations. 